\title{
Optimal Groundwater Remediation Network Design using Selective Membranes
}

Eugenio Bringas ${ }^{a}$, Ramkumar Karuppiah ${ }^{b}, M^{a}$ Fresnedo San Román ${ }^{a^{*}}$, Inmaculada Ortiz $^{a}$, Ignacio E. Grossmann ${ }^{b}$

a Departamento de Ingeniería Química y Química Inorgánica, ETSII y T, Universidad de Cantabria, 39005 Santander, Spain

${ }^{b}$ Department of Chemical Engineering, Carnegie Mellon University, Pittsburgh, Pennsylvania 15213, USA

*Author to whom correspondence should be addressed. E-mail: sanromm@unican.es. 


\begin{abstract}
This work deals with the optimal synthesis of groundwater remediation networks for the valorization of anionic pollutants by means of emulsion pertraction technology using hollow fiber modules (HFM). Superstructures that incorporate all possible design alternatives are proposed. The aim of this work is to obtain a minimum cost groundwater remediation network that allows treatment of groundwater to required levels, and also, a contaminant rich solution that can be used for further processing. The optimization of the superstructure is initially formulated as a nonconvex nonlinear programming (NLP) problem. This rigorous NLP model is simplified using some assumptions to get a simplified model which is globally optimized using a Lagrangean decomposition algorithm. This globally optimal solution is used as an initialization point for optimizing the rigorous NLP problem. Three cases involving different numbers of HFM are studied to determine a cost optimized network with an optimal number of modules.
\end{abstract}

Keywords: Groundwater, Emulsion Pertraction, Anionic Pollutants, NLP, Global Optimization, Lagrangean Decomposition

\title{
1. Introduction
}


Groundwater and in general wastewater streams containing metallic contaminants are treated before release into the environment not only to remove contaminants to meet disposal requirements, but also to recover the metallic contaminants for selling them or re-using them in industrial applications. ${ }^{1}$ Although different processes exist for the treatment of aqueous streams containing metallic contaminants, one of the proven technologies that allows efficient removal of the contaminants is membrane based solvent extraction using microporous hollow fiber (HF) contactors. ${ }^{2,3}$ In this work, we use an emulsion pertraction technology (EPT) to carry out the simultaneous extraction and backextraction of a contaminant in a HF module. In this particular EPT process, the aqueous groundwater stream containing the contaminants is separated from an emulsion phase by a hydrophobic microporous membrane. The emulsion phase consists of an organic phase containing a dissolved selective extractant, and a stripping solution, which is present in the form of dispersed droplets. The solute is transferred from the aqueous feed solution to the organic phase, and it is then transported inside the stripping solution droplets. ${ }^{4-6}$

While the application of the above-mentioned technology and the mass transport phenomena involved in the separation process have been extensively studied ${ }^{5-8}$, there is still limited information on the optimization of membrane based solvent extraction processes. ${ }^{9}$ The optimization of a non-dispersive solvent extraction (NDSX) pilot plant operating in co-current semicontinuous mode and in continuous mode using a nonlinear programming (NLP) model has been dealt with previously. ${ }^{10,11}$ Alonso et al. ${ }^{1}$ have addressed the problem of the design of a semicontinuous NDSX process using a time invariant mixed-integer nonlinear programming (MINLP) model. Ortiz et al. ${ }^{12}$ and Eliceche et al. ${ }^{13}$ have proposed NLP model for the optimization of the membrane area of 
an EPT process containing two treatment units. San Román et al. ${ }^{14}$ proposed an NLP model, similar to the one proposed by Wang and Smith ${ }^{15}$, for a EPT based wastewater treatment system. In all the above mentioned cases, global optimality is not guaranteed.

In other work, different strategies were used to solve the groundwater remediation network synthesis problem to optimality. Galán and Grossmann ${ }^{16}$ have presented an NLP and MINLP model for optimizing the superstructures given by Wang and Smith ${ }^{14}$. These authors suggested an effective heuristic procedure based on mathematical programming to obtain the optimal design of a distributed wastewater treatment network. The superstructure optimization problem was further extended by Lee and Grossmann ${ }^{17}$, who formulated the decentralized wastewater treatment network as a non-convex Generalized Disjunctive Program (GDP) and solved the problem to global optimality.

In this paper, we propose network superstructures for the aqueous and the emulsion streams for the design of an optimal emulsion pertraction process. We model the optimization of the network as an NLP problem where we use discretized differential and algebraic equations to model the membrane modules that remove the contaminants from groundwater. This NLP is highly nonlinear and nonconvex, and therefore we reformulate it to obtain a simplified model with fewer nonconvexities. We then propose a spatial branch and bound algorithm based on Lagrangean decomposition to solve this simplified model to global optimality. In the proposed approach, we generate tight lower bounds on the global optimum using a decomposition technique, which are then made to converge to the solution in a branch and bound setting. Finally, the globally optimal solution of the simplified NLP is used as an initialization point for optimizing the rigorous model. 
The proposed solution strategy is used to solve different example networks containing different number of hollow fiber modules. In all of these examples, we studied the removal of anionic hexavalent chromium from polluted groundwater. The groundwater remediation process results in treated groundwater, and a chromium rich stream that can be re-used in some industrial application.

\section{Problem Statement}

In this work, we consider the optimal synthesis of an emulsion pertraction system that consists of a specified number of hollow fiber modules (MOD), mixers (MU) and splitters (SU), with various possible interconnections between these units. We are given a groundwater stream whose flowrate and contaminant composition is known. This stream has to be treated using the given hollow fiber modules before the effluent stream can be discharged into the environment such that the contaminant levels present in the discharge do not exceed pre-specified limits. The specific objective of this work is to identify the interconnections between all the units in the system, and to determine the flowrates and the contaminant compositions of all the streams in the network, such that the total cost of groundwater remediation is minimized. In order to address this problem, we propose network superstructures for the aqueous groundwater stream and an emulsion stream (consisting of an organic phase and a stripping agent), which flow counter-currently inside a hollow fiber module where the transfer of contaminant takes place between the aqueous phase and the emulsion phase. Figures 1 and 2 show the network superstructures for the aqueous feed solution and the emulsion phase, respectively, for a large-scale system with four treatment modules. In these figures, although we have shown separate 
superstructures for the aqueous phase and the emulsion phase, these correspond to different parts of the single overall network superstructure which has to be optimized.

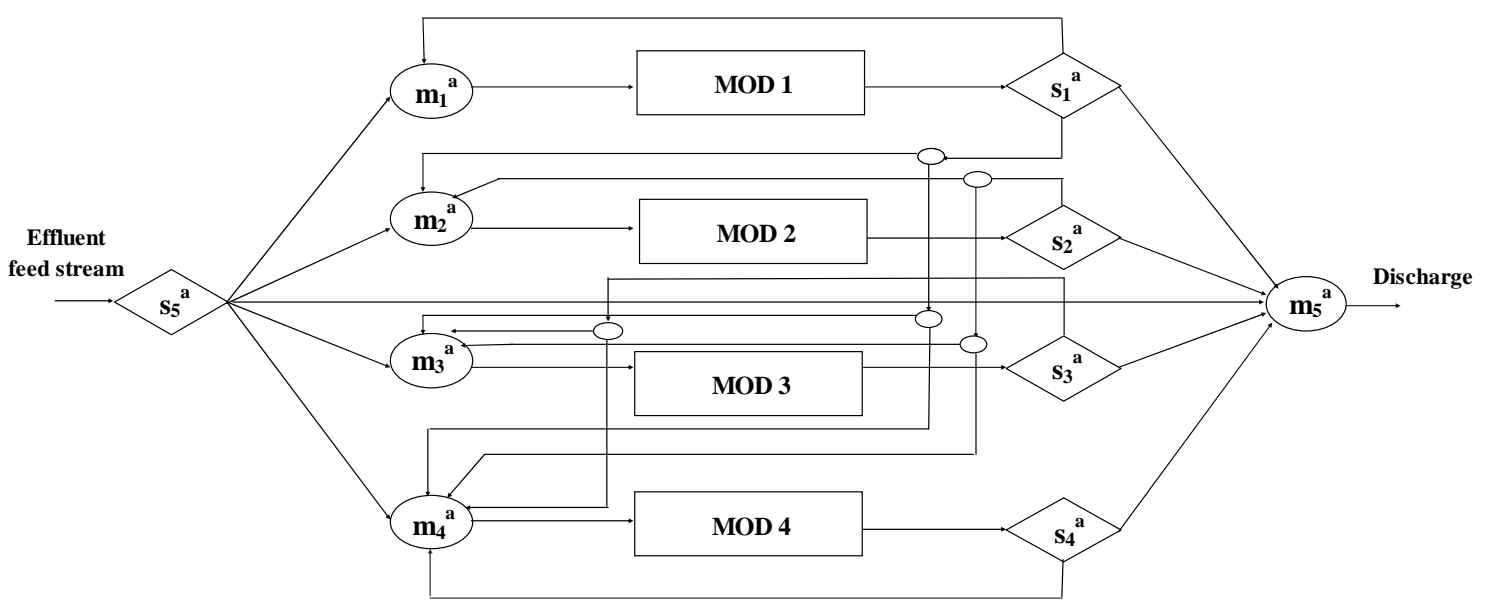

Figure 1. Network superstructure for the aqueous feed solution.

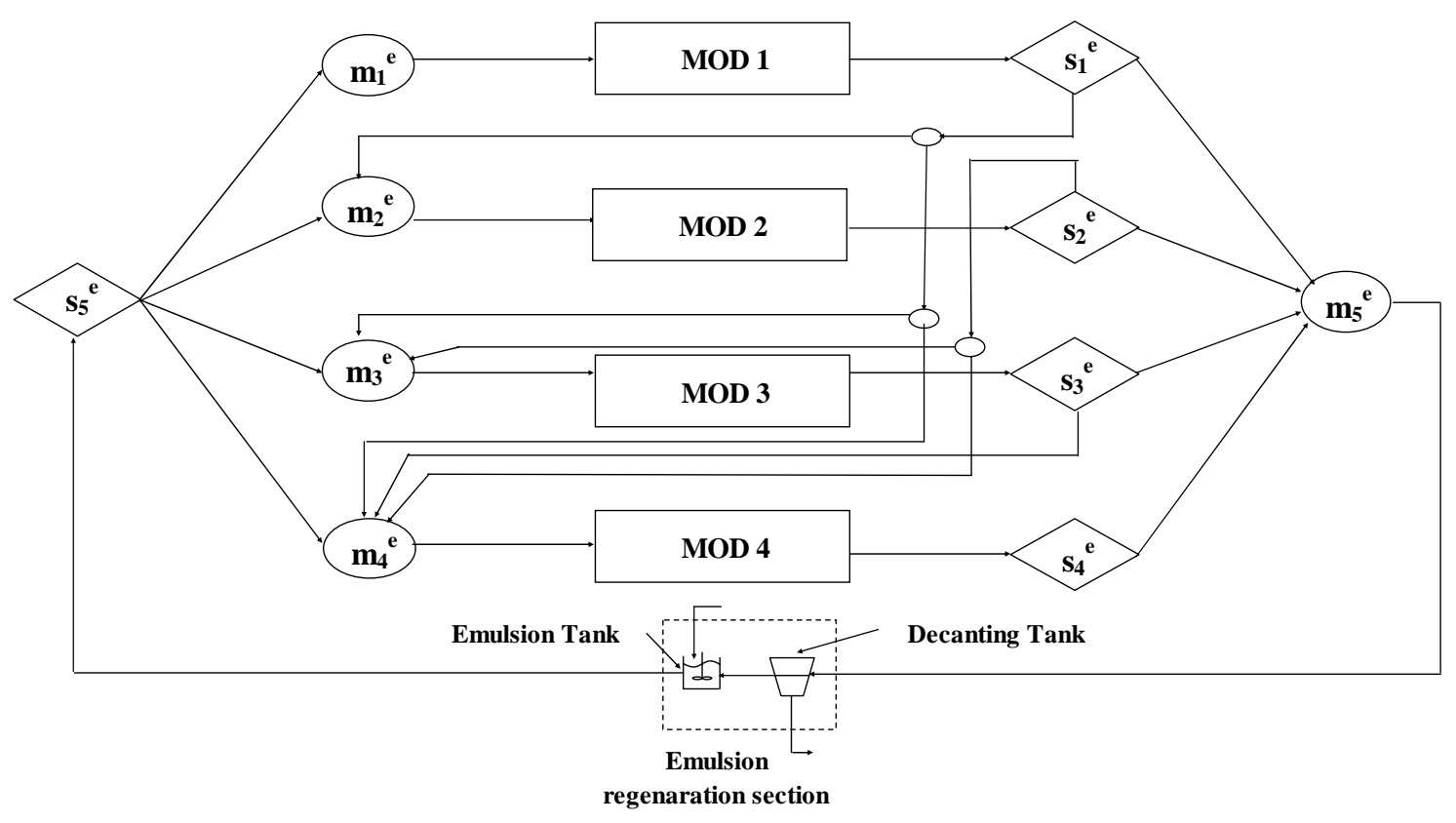

Figure 2. Network superstructure for the emulsion phase.

As can be seen from Figure 1, the aqueous groundwater feed stream is split into various streams that are directed to different mixers $\left(m_{1}^{a}\right.$ to $\left.m_{5}^{a}\right)$ in the system. The outlet 
streams of the mixers, $m_{1}^{a}$ to $m_{4}^{a}$ are directed to the treatment modules and the outlet stream from each treatment module is directed to splitters that direct the water to the various mixers in the network. ${ }^{16}$ There is also an aqueous discharge stream (outlet stream from mixer $m_{5}^{a}$ ) which is the treated groundwater being discharged into the environment. Further, as shown in Figure 2, a similar network superstructure is constructed for the emulsion phase. The emulsion that is used for extracting the contaminants from the aqueous effluent stream, is prepared by dispersing a stripping agent in an organic phase in a ratio of 1:4 by volume. The organic phase consists of an anionic extractant and emulsion modifiers dissolved together in a solvent, while the stripping phase is a solution of a back-extraction agent. ${ }^{8}$ The contaminants pass from the aqueous stream into the stripping phase in the emulsion through the intermediate organic phase. Also, in the emulsion phase network superstructure, there exists a particular sub-system called the emulsion regeneration section. In this section, the contaminant rich stripping phase, produced by the transfer of contaminant from the groundwater streams to the stripping phase, is decanted while the organic phase is recycled. A fresh clean stripping solution is then mixed with the organic phase forming a new emulsion inside the emulsion tank as shown in Figure 2. From the two figures, it can be seen that we have separate mixers and splitters for the aqueous and the emulsion streams and the only common equipment for these two sets of streams are the hollow fiber modules.

For this synthesis problem, the polluted aqueous feed stream is characterized by a known flowrate and a given concentration of an anionic pollutant. This groundwater stream has to be treated inside the modules such that the solute concentration in the discharge stream into the environment has to be less than or equal to the value imposed 
by regulations. Furthermore, the concentration of the contaminant in the stripping phase at the outlet of the decanting tank should be greater than a specified limit in order for the contaminant rich stripping solution to be reused elsewhere. Hence, lower bounds are imposed on the solute concentration in this particular stripping solution. Other constraints that need to be satisfied are that the mass balances in all the units in the system must hold. Finally, the aim of the design problem is to minimize the design and operation cost of the network.

We model the optimization of the network as a continuous NLP. Certain simplifying assumptions are made before modeling the system:

(i) The cost of constructing the network is determined by the total membrane area of all the hollow fiber modules. The operating and environmental costs are also taken into account. The costs of pumping and piping are neglected.

(ii) There is no transfer of pollutant from the organic phase to the stripping phase inside the emulsion tank or the decanting tank.

(iii) The network is operated under isothermal and isobaric conditions.

We initially model the problem in a rigorous way making use of differential and algebraic equations for the mass balances in the hollow fiber modules and the other units in the system. The resulting NLP is highly nonlinear and nonconvex which makes it very difficult to solve to global optimality for large industrial size treatment networks. For this reason we simplify the model using some assumptions and solve the resulting model to global optimality. This globally optimal solution is used as an initialization point for optimizing the rigorous model. The proposed solution strategy is shown in Figure 3. 


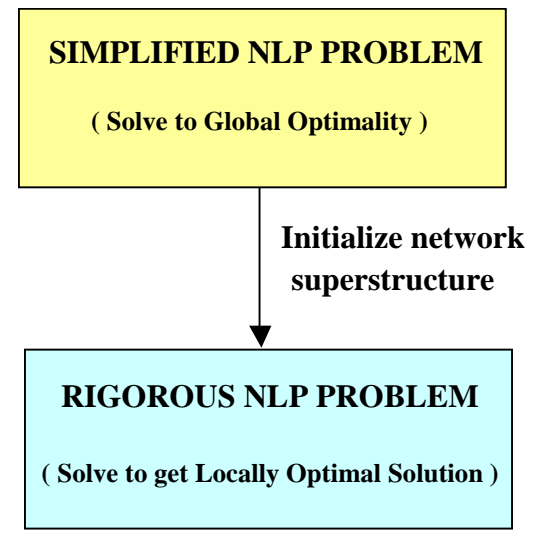

Figure 3. Solution strategy.

Having outlined the solution strategy, we develop the rigorous and the simplified models.

\section{Model}

In this work, two different models are used to describe the network: i) a rigorous model where the membrane modules are modeled using differential equations which are discretized to obtain algebraic equations and, ii) a simplified model where the contaminant transfer between the different phases inside the membrane modules is modeled simply making use of fixed solute transfer coefficients to define the transfer of solute between the aqueous and stripping phases. It is to be noted that the model is written for a single contaminant system since the problem in this work involves a single contaminant in the effluent stream. However, the model can very easily be extended for networks involving multiple contaminants since the basic structure of the constraints remains the same and only some additional constraints are introduced for the additional contaminants.

\subsection{Rigorous Model}


As mentioned previously, the process network consists of splitters, mixers and membrane modules. The emulsion pertraction model consists of a set of algebraic and differential equations. In order to formulate the model as a continuous NLP, the differential equations are replaced by algebraic equations that are obtained by discretizing the differential equations that pertain to the spatial variation of the contaminant concentration inside the hollow fiber modules. To model the optimization problem, we use the total flows and the contaminant composition of the streams in the network.

\section{Objective Function}

The objective of the optimization problem is to minimize the costs of constructing and operating the network and the environmental costs. The total capital cost is considered proportional to the total area of the hollow fiber modules while the operating cost of the process is taken to be proportional to the solute concentration in the organic phase at the inlet of the regeneration section. The concentration of the contaminant in the aqueous discharge stream is representative of the environmental cost of waste disposal.

$$
\min \varphi=\sum_{\mathrm{t} \in \mathrm{MOD}} \mathrm{A}_{\mathrm{t}}+\mathrm{K} \cdot\left(\mathrm{C}_{\mathrm{a}}^{\text {out }}+\mathrm{C}_{\mathrm{o}}^{\mathrm{r}_{\mathrm{in}}}\right)
$$

Here $A_{t}$ is the area of a membrane module ' $t$ ' and $C_{a}^{\text {out }}$ and $C_{o}^{r_{i n}}$ are the contaminant concentrations in the aqueous discharge stream and organic phase at the inlet of the emulsion regeneration section, respectively. Note that the constant $K$ is a scaling factor that places the areas and concentrations in comparable terms. In this work, a value of $K=$ 1 is used.

\section{Membrane Modules}

The hollow fiber modules are used to remove the contaminants from the aqueous feed solution by concentrating them in the stripping phase inside the emulsion. A 
contaminant diffuses through the aqueous phase stagnant layer to the interface with the membrane where it reacts with the organic carrier. Then, the organometallic complexes formed as a result of this reaction, diffuse through the membrane and the organic phase stagnant layer towards the emulsion droplets where they react with the stripping agent, thereby allowing recovery of the solute and the organic extractant. A schematic representation of a hollow fiber module is given in Figure 4. As shown in this figure, a module $t \in M O D$ has an inlet aqueous stream $k \in t_{i n}^{a}$ and an outlet aqueous stream $i \in t_{\text {out }}^{a}$. There is also an inlet emulsion stream $k^{\prime} \in t_{\text {in }}^{e}$ entering the module and an outlet emulsion stream $i^{\prime} \in t_{\text {out }}^{e}$ leaving the module. The emulsion phase $(e)$ contains the organic (o) and the stripping $(g)$ phases and flows counter-currently to the aqueous stream inside the membrane module.

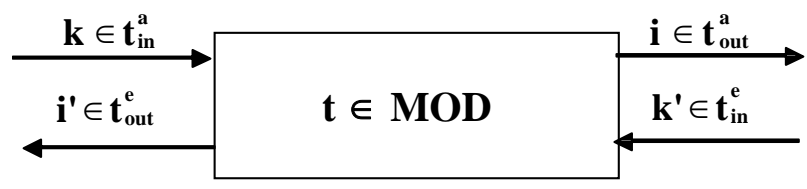

Figure 4. Hollow Fiber Modules.

The mathematical model for a membrane module includes the following equations: i) equation for mass transfer flux through the aqueous phase stagnant layer, ii) equations for determining the equilibrium parameters of the extraction reactions between the solute and the extractant agent to form the organic complex, iii) mass transfer equation for the flux within the organic membrane, iv) equation for mass transfer through the organic phase stagnant layer, v) solute mass balances inside the module, and vi) empirical relationships between the area, volume and the length of the modules. 
The extraction reaction between the anionic solute $A^{-}$and the anionic extractant $\overline{R_{3} N}$ is assumed to take place by means of the following equation:

$\mathrm{A}^{\mathrm{n}-}+\mathrm{nH}^{+}+\mathrm{n} \overline{\mathrm{R}_{3} \mathrm{~N}} \Leftrightarrow \overline{\left(\mathrm{R}_{3} \mathrm{NH}\right)_{\mathrm{n}} \mathrm{A}}$

where the bar above a certain component is used to refer to the species in the organic phase.

The mass transfer flux in the aqueous phase stagnant layer inside module ' $t$ ' at an axial position ' $z$ ' can be described by Fick's law:

$\mathrm{J}_{\mathrm{a}}^{\mathrm{t}}(\mathrm{z})=\mathrm{K}_{\mathrm{L}} \cdot\left(\mathrm{C}_{\mathrm{a}}^{\mathrm{t}}(\mathrm{z})-\mathrm{C}_{\mathrm{a}}^{\mathrm{t}^{*}}(\mathrm{z})\right) \quad \forall \mathrm{t} \in \mathrm{MOD}$

where $C_{a}^{t}(z)$ is the bulk concentration of the solute in the aqueous phase inside the treatment module ' $t$ ' at position ' $\mathrm{z}$ ', $\mathrm{C}_{\mathrm{a}}^{\mathrm{t*}}(\mathrm{z})$ is the solute concentration at the interface between the aqueous phase and the membrane inside the module ' $t$ ' at the axial position ' $z$ ' and $K_{L}$ is the mass transfer coefficient in the aqueous phase stagnant layer. In the organic membrane, the mass transfer is given by:

$$
\mathrm{J}_{\mathrm{o}}^{\mathrm{t}}(\mathrm{z})=\mathrm{K}_{\mathrm{M}} \cdot\left(\mathrm{C}_{\mathrm{o}}^{\mathrm{t}^{*}}(\mathrm{z})-\mathrm{C}_{\mathrm{o}}^{\mathrm{t}}(\mathrm{z})\right) \quad \forall \mathrm{t} \in \mathrm{MOD}
$$

Here, $\mathrm{C}_{\mathrm{o}}^{\mathrm{t}^{*}}(\mathrm{z})$ is the solute concentration in the organic phase at the membrane interface, which is in equilibrium with $\mathrm{C}_{\mathrm{a}}^{\mathrm{t}^{*}}(\mathrm{z})$ at the axial position ' $\mathrm{z}$ ', $\mathrm{C}_{\mathrm{o}}^{\mathrm{t}}(\mathrm{z})$ is the solute bulk concentration in the organic phase inside the membrane module ' $t$ ' at position ' $z$ ', and $K_{M}$ is the membrane mass transport coefficient. The back-extraction reaction takes place between the organometallic complex, $\overline{\left(R_{3} N H\right) A}$, and the stripping agent, allowing the recovery of the solute and the anionic extractant $\left(\overline{R_{3} N}\right)$. This reaction is considered to be totally shifted to the right since the concentration of stripping agent is much higher 
than the concentrations of the other species taking part in the reaction. Therefore, it can be assumed that the concentration of the organometallic species at the interface of the stripping droplets is zero. Hence, the mass transfer flux in the organic phase stagnant layer at the organic-stripping interface in the emulsion can be expressed as follows:

$\mathrm{J}_{\mathrm{g}}^{\mathrm{t}}(\mathrm{z})=\mathrm{K}_{\mathrm{o}} \cdot\left(\mathrm{C}_{\mathrm{o}}^{\mathrm{t}}(\mathrm{z})-0\right)=\mathrm{K}_{\mathrm{o}} \cdot \mathrm{C}_{\mathrm{o}}^{\mathrm{t}}(\mathrm{z}) \quad \forall \mathrm{t} \in \mathrm{MOD}$

where $K_{o}$ is the mass transfer coefficient in the organic phase stagnant layer.

Assuming pseudo-steady state:

$\mathrm{J}_{\mathrm{a}}^{\mathrm{t}}(\mathrm{z})=\mathrm{J}_{\mathrm{o}}^{\mathrm{t}}(\mathrm{z}) \Rightarrow \mathrm{K}_{\mathrm{L}} \cdot\left(\mathrm{C}_{\mathrm{a}}^{\mathrm{t}}(\mathrm{z})-\mathrm{C}_{\mathrm{a}}^{\mathrm{t}^{*}}(\mathrm{z})\right)=\mathrm{K}_{\mathrm{M}} \cdot\left(\mathrm{C}_{\mathrm{o}}^{\mathrm{t}^{*}}(\mathrm{z})-\mathrm{C}_{\mathrm{o}}^{\mathrm{t}}(\mathrm{z})\right) \quad \forall \mathrm{t} \in \mathrm{MOD}$

The interfacial equilibrium solute concentrations at the interface between the aqueous phase and the membrane are related by the following expression:

$$
\mathrm{K}_{\mathrm{eq}}=\frac{\overline{\left[\left(\mathrm{R}_{3} \mathrm{NH}\right)_{\mathrm{n}} \mathrm{A}\right]^{*}}}{\left[\mathrm{R}_{3} \mathrm{~N}\right]^{* \mathrm{n}} \cdot\left[\mathrm{H}^{+}\right]^{* \mathrm{n}} \cdot\left[\mathrm{A}^{-}\right]^{*}}=\frac{\mathrm{C}_{\mathrm{o}}^{\mathrm{t}^{*}}(\mathrm{z})}{\left[\mathrm{C}_{\mathrm{FE}}^{\mathrm{t}^{*}}(\mathrm{z})\right]^{\mathrm{n}} \cdot\left[\mathrm{C}_{\mathrm{aH}}^{\mathrm{t}^{*}}(\mathrm{z})\right]^{\mathrm{n}} \cdot \mathrm{C}_{\mathrm{a}}^{\mathrm{t}^{*}}(\mathrm{z})} \quad \forall \mathrm{t} \in \mathrm{MOD}
$$

In the above expression, $\mathrm{C}_{\mathrm{FE}}^{\mathrm{t}^{*}}(\mathrm{z})$ and $\mathrm{C}_{\mathrm{aH}}^{\mathrm{t}}(\mathrm{z})$ stand for the equilibrium concentration of the free extractant at the interface of the aqueous phase and the membrane in module ' $t$ ' at the axial position ' $z$ ' and the equilibrium concentration of hydrogen ions at the aqueous phase-membrane interface in module ' $t$ at position ' $z$ ', respectively. $K_{e q}$ is the equilibrium parameter of the extraction reaction between the anionic solute and the organic extractant.

The interfacial equilibrium concentration of the hydrogen ions at the interface between the aqueous phase and the membrane can be related to the interfacial concentration of the solute by means of the following expression:

$$
\mathrm{K}_{\mathrm{L}} \cdot\left(\mathrm{C}_{\mathrm{a}}^{\mathrm{t}}(\mathrm{z})-\mathrm{C}_{\mathrm{a}}^{\mathrm{t}^{*}}(\mathrm{z})\right)=\mathrm{K}_{\mathrm{LH}} \cdot\left(\mathrm{C}_{\mathrm{aH}}^{\mathrm{t}}(\mathrm{z})-\mathrm{C}_{\mathrm{aH}}^{\mathrm{t}^{*}}(\mathrm{z})\right) \quad \forall \mathrm{t} \in \mathrm{MOD}
$$


where $K_{L H}$ is the mass transfer coefficient of the hydrogen ions in the aqueous phase stagnant layer. It is to be noted that all the contaminant concentrations in the above equations of the rigorous model are taken to be functions of ' $z$ ' which is the distance along the membrane length from the inlet point of the aqueous stream into the membrane.

The solute mass balances in the hollow fiber modules are expressed by means of differential equations that are subsequently replaced by algebraic equations. The spatial variation of the contaminant concentrations within the module is discretized using a first order forward finite difference scheme. As a consequence of the steady state assumption, the variation of the solute concentration with time is neglected. Since the flowrates of the inlet and outlet streams for a hollow fiber module are equal, the nonlinear algebraic equations obtained as a result of the discretization can be written as follows:

Aqueous feed solution

$\mathrm{F}_{\mathrm{a}}^{\mathrm{k}}=\mathrm{F}_{\mathrm{a}}^{\mathrm{i}}=\mathrm{F}_{\mathrm{a}}^{\mathrm{t}} \quad \forall \mathrm{t} \in \operatorname{MOD}, \mathrm{i} \in \mathrm{t}_{\text {out }}^{\mathrm{a}}, \mathrm{k} \in \mathrm{t}_{\text {in }}^{\mathrm{a}}$

$\mathrm{F}_{\mathrm{a}}^{\mathrm{t}} \frac{\mathrm{C}_{\mathrm{a}}^{\mathrm{t}}\left(\mathrm{z}+\Delta \mathrm{z}_{\mathrm{t}}\right)-\mathrm{C}_{\mathrm{a}}^{\mathrm{t}}(\mathrm{z})}{\Delta \mathrm{z}_{\mathrm{t}}}=-\frac{\mathrm{A}_{\mathrm{t}}}{\mathrm{L}_{\mathrm{t}}} \cdot \mathrm{K}_{\mathrm{L}} \cdot\left(\mathrm{C}_{\mathrm{a}}^{\mathrm{t}}(\mathrm{z})-\mathrm{C}_{\mathrm{a}}^{\mathrm{t}^{*}}(\mathrm{z})\right), \quad \mathrm{C}_{\mathrm{a}}^{\mathrm{t}}(\mathrm{z}=0)=\mathrm{C}_{\mathrm{a}}^{\mathrm{k}} \quad \forall \mathrm{t} \in \mathrm{MOD}, \mathrm{k} \in \mathrm{t}_{\mathrm{in}}^{\mathrm{a}}$

$\mathrm{F}_{\mathrm{a}}^{\mathrm{t}} \cdot \frac{\mathrm{C}_{\mathrm{aH}}^{\mathrm{t}}\left(\mathrm{z}+\Delta \mathrm{z}_{\mathrm{t}}\right)-\mathrm{C}_{\mathrm{aH}}^{\mathrm{t}}(\mathrm{z})}{\Delta \mathrm{z}_{\mathrm{t}}}=-\frac{\mathrm{A}_{\mathrm{t}}}{\mathrm{L}_{\mathrm{t}}} \cdot \mathrm{K}_{\mathrm{LH}} \cdot\left(\mathrm{C}_{\mathrm{aH}}^{\mathrm{t}}(\mathrm{z})-\mathrm{C}_{\mathrm{aH}}^{\mathrm{t}^{*}}(\mathrm{z})\right), \quad \mathrm{C}_{\mathrm{aH}}^{\mathrm{t}}(\mathrm{z}=0)=\mathrm{C}_{\mathrm{aH}}^{\mathrm{k}} \quad \forall \mathrm{t} \in \mathrm{MOD}, \mathrm{k} \in \mathrm{t}_{\mathrm{in}}^{\mathrm{a}}$

Here $F_{a}^{t}$ is the flowrate of the aqueous phase solution inside the module ' $t$ ', while $C_{a}^{t}(\mathrm{z})$ and $C_{a H}^{t}(\mathrm{z})$ are the concentrations of the solute and the hydrogen ions, respectively, in the aqueous phase inside the module ' $t$ ' at the axial position ' $z$ '. $\Delta z_{t}$ is an infinitesimally small distance taken along the axial dimension of the membrane inside the module ' $t$ ' that can be calculated using to the following equation: 
$\Delta \mathrm{z}_{\mathrm{t}}=\frac{\mathrm{L}_{\mathrm{t}}}{\mathrm{N}}$

where $\mathrm{N}$ is the number of divisions along the axial dimension of the membrane.

Organic phase

$$
\begin{aligned}
& \mathrm{F}_{\mathrm{o}}^{\mathrm{k}^{\prime}}=\mathrm{F}_{\mathrm{o}}^{\mathrm{i}^{\prime}}=\mathrm{F}_{\mathrm{o}}^{\mathrm{t}} \quad \forall \mathrm{t} \in \mathrm{MOD}, \mathrm{i}^{\prime} \in \mathrm{t}_{\mathrm{out}}^{\mathrm{e}}, \mathrm{k}^{\prime} \in \mathrm{t}_{\mathrm{in}}^{\mathrm{e}} \\
& \mathrm{F}_{\mathrm{o}}^{\mathrm{t}} \cdot \frac{\mathrm{C}_{\mathrm{o}}^{\mathrm{t}}\left(\mathrm{z}+\Delta \mathrm{z}_{\mathrm{t}}\right)-\mathrm{C}_{\mathrm{o}}^{\mathrm{t}}(\mathrm{z})}{\Delta \mathrm{z}_{\mathrm{t}}}=-\frac{\mathrm{A}_{\mathrm{t}}}{\mathrm{L}_{\mathrm{t}}} \cdot \mathrm{K}_{\mathrm{L}} \cdot\left(\mathrm{C}_{\mathrm{a}}^{\mathrm{t}}(\mathrm{z})-\mathrm{C}_{\mathrm{a}}^{\mathrm{t}^{*}}(\mathrm{z})\right)+\frac{\mathrm{V}_{\mathrm{g}, \mathrm{t}} \cdot\left(\mathrm{K}_{\mathrm{o}} \cdot \mathrm{A}_{\mathrm{v}}\right)}{\mathrm{L}_{\mathrm{t}}} \cdot \mathrm{C}_{\mathrm{o}}^{\mathrm{t}}(\mathrm{z}), \\
& \quad \mathrm{C}_{\mathrm{o}}^{\mathrm{t}}(\mathrm{z}=\mathrm{L})=\mathrm{C}_{\mathrm{o}}^{\mathrm{k}^{\prime}} \quad \forall \mathrm{t} \in M O D, \mathrm{k}^{\prime} \in \mathrm{t}_{\text {in }}^{\mathrm{e}}
\end{aligned}
$$

Here $F_{o}^{t}$ is the flowrate of the organic phase inside the module ' $t$ ', while $C_{o}^{t}(\mathrm{z})$ is the solute concentration in the organic phase inside the module ' $t$ ' at the axial position ' $z$ '. $V_{g, t}$ is the volume of the stripping agent inside module ' $t$ '.

Stripping phase

$$
\begin{aligned}
& \mathrm{F}_{\mathrm{g}}^{\mathrm{k}^{\prime}}=\mathrm{F}_{\mathrm{g}}^{\mathrm{i}^{\prime}}=\mathrm{F}_{\mathrm{g}}^{\mathrm{t}} \quad \forall \mathrm{t} \in \mathrm{MOD}, \mathrm{i}^{\prime} \in \mathrm{t}_{\text {out }}^{\mathrm{e}}, \mathrm{k}^{\prime} \in \mathrm{t}_{\mathrm{in}}^{\mathrm{e}} \\
& \mathrm{F}_{\mathrm{g}}^{\mathrm{t}} \cdot \frac{\mathrm{C}_{\mathrm{g}}^{\mathrm{t}}\left(\mathrm{z}+\Delta \mathrm{z}_{\mathrm{t}}\right)-\mathrm{C}_{\mathrm{g}}^{\mathrm{t}}(\mathrm{z})}{\Delta \mathrm{z}_{\mathrm{t}}}=-\frac{\mathrm{V}_{\mathrm{g}, \mathrm{t}} \cdot\left(\mathrm{K}_{\mathrm{o}} \cdot \mathrm{A}_{\mathrm{v}}\right)}{\mathrm{L}_{\mathrm{t}}} \cdot \mathrm{C}_{\mathrm{o}}^{\mathrm{t}}(\mathrm{z}), \quad \mathrm{C}_{\mathrm{g}}^{\mathrm{t}}(\mathrm{z}=\mathrm{L})=\mathrm{C}_{\mathrm{g}}^{\mathrm{k}^{\prime}} \quad \forall \mathrm{t} \in \mathrm{MOD}, \mathrm{k}^{\prime} \in \mathrm{t}_{\text {in }}^{\mathrm{e}}
\end{aligned}
$$

In the above equations, $F_{g}^{t}$ is the flowrate of the stripping phase inside the module ' $t$ ', while $C_{g}^{t}(\mathrm{z})$ is the solute concentration in the stripping phase inside the module ' $t$ ' at axial position ' $z$ '.

The empirical relationships between the effective membrane area, the effective length and the effective volume of the shell side of the hollow fiber modules are given by equations (13) and (14): 
$\mathrm{L}_{\mathrm{t}}=0.11 \cdot \ln \left(\mathrm{A}_{\mathrm{t}}\right)+0.09 \quad \forall \mathrm{t} \in \mathrm{MOD}$

$\mathrm{V}_{\mathrm{g}, \mathrm{t}}=1.510^{-5} \cdot \mathrm{A}_{\mathrm{t}} \quad \forall \mathrm{t} \in \mathrm{MOD}$

\section{$\underline{\text { Mixers }}$}

A mixer $m^{a} \in M U^{a}$ belongs to the aqueous phase network and consists of a set of inlet streams $i \in m_{i n}^{a}$ and an outlet stream $k \in m_{\text {out }}^{a}$. For the emulsion phase of the network, a mixer $m^{e} \in M U^{e}$ consists of a set of inlet streams $i \in m_{i n}^{e}$ and an outlet stream $k \in m_{\text {out }}^{e}$.

The overall mass balances for the mixers $m^{a}$ and $m^{e}$ are given by equations (15) and (16), respectively, where $F_{a}^{i}$ is the flowrate of the aqueous stream $i$ while $F_{p}^{i}$ denotes the flow of phase $p$ in an emulsion stream $i$.

$$
\begin{aligned}
& \mathrm{F}_{\mathrm{a}}^{\mathrm{k}}=\sum_{\mathrm{i} \in \mathrm{m}_{\mathrm{in}}^{\mathrm{a}}} \mathrm{F}_{\mathrm{a}}^{\mathrm{i}} \quad \forall \mathrm{m}^{\mathrm{a}} \in \mathrm{MU}^{\mathrm{a}}, \mathrm{k} \in \mathrm{m}_{\text {out }}^{\mathrm{a}} \\
& \mathrm{F}_{\mathrm{p}}^{\mathrm{k}}=\sum_{\mathrm{i} \in \mathrm{m}_{\mathrm{in}}^{\mathrm{e}}} \mathrm{F}_{\mathrm{p}}^{\mathrm{i}} \quad \forall \mathrm{m}^{\mathrm{e}} \in \mathrm{MU}^{\mathrm{e}}, \mathrm{k} \in \mathrm{m}_{\text {out }}^{\mathrm{e}}, \forall \mathrm{p} \in\{\mathrm{o}, \mathrm{g}\}
\end{aligned}
$$

The following equations represent the solute mass balances in the mixers $m^{a}$ and $m^{e}$ for the aqueous and emulsion phases, respectively.

$$
\begin{aligned}
& \mathrm{C}_{\mathrm{a}}^{\mathrm{k}} \cdot \mathrm{F}_{\mathrm{a}}^{\mathrm{k}}=\sum_{\mathrm{i} \in \mathrm{m}_{\mathrm{in}}^{\mathrm{a}}} \mathrm{C}_{\mathrm{a}}^{\mathrm{i}} \cdot \mathrm{F}_{\mathrm{a}}^{\mathrm{i}} \quad \forall \mathrm{m}^{\mathrm{a}} \in \mathrm{MU}^{\mathrm{a}}, \mathrm{k} \in \mathrm{m}_{\text {out }}^{\mathrm{a}} \\
& \mathrm{C}_{\mathrm{p}}^{\mathrm{k}} \cdot \mathrm{F}_{\mathrm{p}}^{\mathrm{k}}=\sum_{\mathrm{i} \in \mathrm{m}_{\text {in }}^{\mathrm{e}}} \mathrm{C}_{\mathrm{p}}^{\mathrm{i}} \cdot \mathrm{F}_{\mathrm{p}}^{\mathrm{i}} \quad \forall \mathrm{m}^{\mathrm{e}} \in \mathrm{MU}^{\mathrm{e}}, \mathrm{k} \in \mathrm{m}_{\text {out }}^{\mathrm{e}}, \forall \mathrm{p} \in\{\mathrm{o}, \mathrm{g}\}
\end{aligned}
$$


where $C_{a}^{i}$ is the solute concentration in the aqueous stream $i$ and $C_{p}^{i}$ is the solute concentration in the phase ' $p$ ' of an emulsion stream $i$.

In the aqueous phase, the mass balances for hydrogen ions in the mixers are given by:

$\mathrm{C}_{\mathrm{aH}}^{\mathrm{k}} \cdot \mathrm{F}_{\mathrm{a}}^{\mathrm{k}}=\sum_{\mathrm{i} \in \mathrm{m}_{\mathrm{in}}^{\mathrm{a}}} \mathrm{C}_{\mathrm{aH}}^{\mathrm{i}} \cdot \mathrm{F}_{\mathrm{a}}^{\mathrm{i}} \quad \forall \mathrm{m}^{\mathrm{a}} \in \mathrm{MU}^{\mathrm{a}}, \mathrm{k} \in \mathrm{m}_{\text {out }}^{\mathrm{a}}$

where $C_{a H}^{i}$ is the concentration of the hydrogen ions in the aqueous stream $i$.

\section{Splitters}

A splitter $s^{a} \in S U^{a}$ present in the aqueous stream network consists of an inlet stream $k \in s_{\text {in }}^{a}$ and a set of outlet streams $i \in s_{\text {out }}^{a}$. The splitter $s^{e} \in S U^{e}$ belongs to the emulsion stream network and consists of an inlet stream $k \in s_{i n}^{e}$ and a set of outlet streams $i \in S_{\text {out }}^{e}$.

The overall mass balances for the splitters $s^{a}$ and $s^{e}$ are given by equations (20) and (21), respectively

$$
\begin{aligned}
& \mathrm{F}_{\mathrm{a}}^{\mathrm{k}}=\sum_{\mathrm{i} \in \mathrm{s}_{\text {out }}^{\mathrm{a}}} \mathrm{F}_{\mathrm{a}}^{\mathrm{i}} \quad \forall \mathrm{s}^{\mathrm{a}} \in \mathrm{SU}^{\mathrm{a}}, \mathrm{k} \in \mathrm{s}_{\text {in }}^{\mathrm{a}} \\
& \mathrm{F}_{\mathrm{p}}^{\mathrm{k}}=\sum_{\mathrm{i} \in \mathrm{s}_{\text {out }}^{\mathrm{e}}} \mathrm{F}_{\mathrm{p}}^{\mathrm{i}} \quad \forall \mathrm{s}^{\mathrm{e}} \in \mathrm{SU}^{\mathrm{e}}, \mathrm{k} \in \mathrm{s}_{\text {in }}^{\mathrm{e}}, \forall \mathrm{p} \in\{\mathrm{o}, \mathrm{g}\}
\end{aligned}
$$

The contaminant mass balances in the splitters $s^{a}$ and $s^{e}$, are given by the following equations.

$$
\mathrm{C}_{\mathrm{a}}^{\mathrm{k}}=\mathrm{C}_{\mathrm{a}}^{\mathrm{i}} \quad \forall \mathrm{s}^{\mathrm{a}} \in \mathrm{SU}^{\mathrm{a}}, \mathrm{k} \in \mathrm{s}_{\text {in }}^{\mathrm{a}}, \forall \mathrm{i} \in \mathrm{s}_{\text {out }}^{\mathrm{a}}
$$


$\mathrm{C}_{\mathrm{p}}^{\mathrm{k}}=\mathrm{C}_{\mathrm{p}}^{\mathrm{i}} \quad \forall \mathrm{s}^{\mathrm{e}} \in \mathrm{SU}^{\mathrm{e}}, \mathrm{k} \in \mathrm{s}_{\mathrm{in}}^{\mathrm{e}}, \forall \mathrm{i} \in \mathrm{s}_{\text {out }}^{\mathrm{e}}, \forall \mathrm{p} \in\{\mathrm{o}, \mathrm{g}\}$

The mass balance for the hydrogen ions in the splitters corresponding to the aqueous stream network can be written as follows:

$\mathrm{C}_{\mathrm{aH}}^{\mathrm{k}}=\mathrm{C}_{\mathrm{aH}}^{\mathrm{i}} \quad \forall \mathrm{s}^{\mathrm{a}} \in \mathrm{SU}^{\mathrm{a}}, \mathrm{k} \in \mathrm{s}_{\mathrm{in}}^{\mathrm{a}}, \forall \mathrm{i} \in \mathrm{s}_{\text {out }}^{\mathrm{a}}$

\section{$\underline{\text { Emulsion Regeneration Section }}$}

The emulsion regeneration section is employed to recover the solute rich stripping solution. In this section, the emulsion leaving the treatment modules is first allowed to settle down in a decanting tank. The organic phase is then pumped to the emulsion tank where it is mixed with a fresh stripping solution that is devoid of any contaminant. This new emulsion phase is then recycled to the treatment modules. There is no change in the solute concentration of the organic phase inside this whole section. The concentrated stripping solution is removed from the decanting tank and is used in other processes. Figure 5 shows the schematic diagram of the emulsion regeneration section.

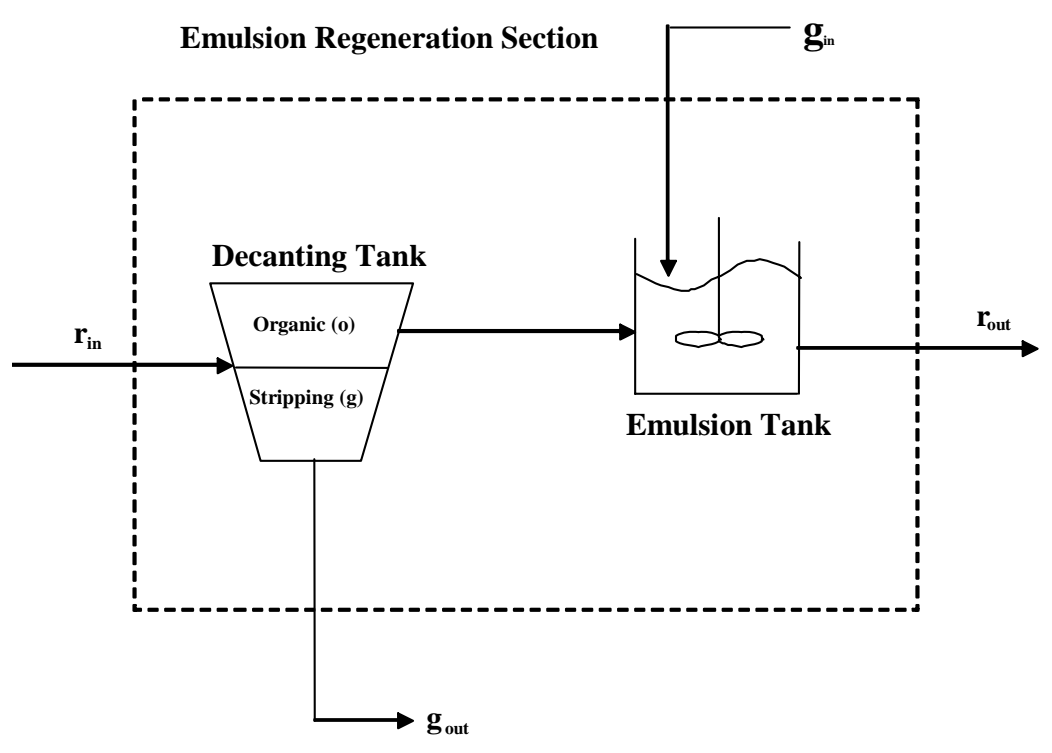


Figure 5. Emulsion regeneration section.

The overall mass balance and the solute mass balances in the emulsion regeneration section are given in equations (25) - (29):

$$
\begin{aligned}
& \mathrm{F}_{\mathrm{p}}^{\mathrm{r}_{\text {in }}}=\mathrm{F}_{\mathrm{p}}^{\mathrm{r}_{\text {out }}} \quad \forall \mathrm{p} \in\{0, \mathrm{~g}\} \\
& \mathrm{C}_{\mathrm{o}}^{\mathrm{r}_{\text {in }}}=\mathrm{C}_{\mathrm{o}}^{\mathrm{r}_{\text {out }}} \\
& \mathrm{F}_{\mathrm{g}}^{\mathrm{r}_{\text {in }}}+\mathrm{F}^{\mathrm{g}_{\text {in }}}=\mathrm{F}_{\mathrm{g}}^{\mathrm{rout}_{\text {out }}}+\mathrm{F}^{\mathrm{g}_{\text {out }}} \\
& \mathrm{C}_{\mathrm{g}}^{\mathrm{r}_{\text {in }}}=\mathrm{C}^{\mathrm{g}_{\mathrm{out}}} \\
& \mathrm{F}_{\mathrm{g}}^{\mathrm{r}_{\text {in }}} \cdot \mathrm{C}_{\mathrm{g}}^{\mathrm{r}_{\text {in }}}+\mathrm{F}^{\mathrm{g}_{\text {in }}} \cdot \mathrm{C}^{\mathrm{g}_{\text {in }}}=\mathrm{F}_{\mathrm{g}}^{\mathrm{r}_{\text {out }}} \cdot \mathrm{C}_{\mathrm{g}}^{\mathrm{r}_{\text {out }}}+\mathrm{F}^{\mathrm{g}_{\text {out }}} \cdot \mathrm{C}^{\mathrm{g}_{\text {out }}}
\end{aligned}
$$

The terms appearing in these equations are defined in the nomenclature.

\section{Flowrate Relationships in the Emulsion Phase}

The ratio of the flowrates of the organic and the stripping phases that make up the emulsion is 4:1 in all the streams in the emulsion network (eq (30)).

$\mathrm{F}_{\mathrm{o}}=4 \cdot \mathrm{F}_{\mathrm{g}}$

Finally, the limits on the contaminant compositions and flowrates of the streams are handled by imposition of lower and upper bounds on all the variables in the model.

The model (P1), given by equations (1)-(30), is a NLP model since equations (3), (6), (7), (10), (12), (13), (17)-(19), and (29) are non-linear. Since these equations involve nonconvex terms, standard NLP algorithms may lead to a local optimum. The local solution to the problem can be obtained using any local NLP solver. ${ }^{18}$ 


\subsection{Simplified Model}

The simplified model for representing the groundwater remediation network is based on the rigorous model, but we take into account some additional assumptions that make the problem easier to solve. The globally optimal solution of the simplified model can then be used as an initial point for solving the rigorous model. The main assumptions made in the simplified model are the following:

(i) For the treatment modules, the extraction and back-extraction steps are modeled using fixed solute transfer coefficients to describe the transfer of the solute from the aqueous solution to the stripping phase in the emulsion.

(ii) There is no spatial variation of the concentration of the contaminant species inside the membrane modules along the length of the membrane as a function of the distance from the inlet of the membrane module. In other words, the concentration of the contaminant species inside the membrane modules is taken to be constant at steady state.

(iii) The solute gets transferred from the aqueous phase to the stripping phase through the intermediate organic phase. Since the concentration of the solute in the organic phase is not required to be known, the mass balances can be written only for the aqueous and stripping phases in order to reduce the number of nonlinear equations. The organic phase flowrates are calculated from the flowrate relationships between the organic and the stripping phases.

(iv) The objective function is defined by taking into account only the operating cost of the network. 


\section{Objective Function}

$\min \phi=\sum_{\mathrm{t} \in \mathrm{MOD}}\left(\mathrm{F}_{\mathrm{a}}^{\mathrm{t}}+4 \cdot \mathrm{F}_{\mathrm{g}}^{\mathrm{t}}\right)$

In the rigorous model, the objective was to minimize the total cost, which was the sum of the capital cost and the operating cost of the network. In the simplified model only the operating cost is taken into account. This cost is considered to be proportional to the flow of aqueous streams inside the modules, and to the flowrate of the organic phase used inside the modules in order to remove the pollutants.

\section{Membrane Modules}

In the simplified model, the membrane modules have the same physical structure as in the rigorous model (see Figure 4), but are now modeled in a simpler manner. The solute concentration in the aqueous and the stripping phases can be calculated using the coefficients $\beta$ defined as follows:

$\beta_{\mathrm{a}}=1-\{$ Extraction Percentage for the solute $/ 100\}$

$\beta_{\mathrm{g}}=1-\{$ Back Extraction Percentage for the solute $/ 100\}$

$\beta_{a}$ is used to describe the transfer of the contaminant from the aqueous stream to the organic phase while $\beta_{g}$ corresponds to the transfer of the contaminant from the organic phase to the stripping phase.

The following equations represent the overall mass balances and the solute mass balances for the aqueous stream and the stripping phase inside the membrane modules:

$$
\begin{aligned}
& \mathrm{F}_{\mathrm{a}}^{\mathrm{i}}=\mathrm{F}_{\mathrm{a}}^{\mathrm{k}}=\mathrm{F}_{\mathrm{a}}^{\mathrm{t}} \quad \forall \mathrm{t} \in \mathrm{MOD}, \mathrm{i} \in \mathrm{t}_{\text {out }}^{\mathrm{a}}, \mathrm{k} \in \mathrm{t}_{\text {in }}^{\mathrm{a}} \\
& \mathrm{C}_{\mathrm{a}}^{\mathrm{i}}=\beta_{\mathrm{a}} \cdot \mathrm{C}_{\mathrm{a}}^{\mathrm{k}} \quad \forall \mathrm{t} \in \mathrm{MOD}, \mathrm{i} \in \mathrm{t}_{\text {out }}^{\mathrm{a}}, \mathrm{k} \in \mathrm{t}_{\text {in }}^{\mathrm{a}}
\end{aligned}
$$


$\mathrm{F}_{\mathrm{g}}^{\mathrm{i}^{\prime}}=\mathrm{F}_{\mathrm{g}}^{\mathrm{k}^{\prime}}=\mathrm{F}_{\mathrm{g}}^{\mathrm{t}} \quad \forall \mathrm{t} \in \mathrm{MOD}, \mathrm{i}^{\prime} \in \mathrm{t}_{\text {out }}^{\mathrm{e}}, \mathrm{k}^{\prime} \in \mathrm{t}_{\text {in }}^{\mathrm{e}}$

$\mathrm{F}_{\mathrm{g}}^{\mathrm{t}} \cdot\left(\mathrm{C}_{\mathrm{g}}^{\mathrm{i}^{\prime}}-\mathrm{C}_{\mathrm{g}}^{\mathrm{k}^{\prime}}\right)=\mathrm{F}_{\mathrm{a}}^{\mathrm{t}} \cdot \mathrm{C}_{\mathrm{a}}^{\mathrm{k}} \cdot\left(1-\beta_{\mathrm{a}}\right) \cdot\left(1-\beta_{\mathrm{g}}\right) \quad \forall \mathrm{t} \in \mathrm{MOD}, \mathrm{i}^{\prime} \in \mathrm{t}_{\text {out }}^{\mathrm{e}}, \mathrm{k}^{\prime} \in \mathrm{t}_{\text {in }}^{\mathrm{e}}, \mathrm{k} \in \mathrm{t}_{\text {in }}^{\mathrm{a}}$

\section{$\underline{\text { Valid Cuts }}$}

An extra constraint (eq (36)) that corresponds to the contaminant material balance for the overall system is incorporated into the simplified model in order to strengthen its relaxation and hence accelerate the convergence of the algorithm employed for the global optimization of the simplified model. ${ }^{19}$

$$
\sum_{\mathrm{t} \in \mathrm{MOD}}\left(1-\beta_{\mathrm{a}}\right) \cdot \mathrm{F}_{\mathrm{a}}^{\mathrm{t}} \cdot \mathrm{C}_{\mathrm{a}}^{\mathrm{k}}=\mathrm{F}_{\mathrm{a}}^{\mathrm{in}} \cdot \mathrm{C}_{\mathrm{a}}^{\mathrm{in}}-\mathrm{F}_{\mathrm{a}}^{\text {out }} \cdot \mathrm{C}_{\mathrm{a}}^{\text {out }} \quad \mathrm{k} \in \mathrm{t}_{\text {in }}^{\mathrm{a}}
$$

Here, $F_{a}^{i n}$ is the flowrate of the inlet aqueous stream entering the network while $C_{a}^{i n}$ is the concentration of the solute in the same inlet aqueous stream. $F_{a}^{\text {out }}$ and $C_{a}^{\text {out }}$ are the total flow and the solute concentration, respectively, in the outlet aqueous discharge stream.

The equations for the mixers, splitters and the emulsion regeneration section are the same as the ones in the rigorous model, but now are only defined for the stripping phase in the emulsion streams and the aqueous streams. The simplified NLP model (P2) is given by equations (15) - (18), (20) - (23), (25), (27) - (29), and (31)-(36). Finally, we apply lower and upper bounds on the variables in the model to handle constraints pertaining to the limits on the flowrates and contaminant compositions.

\section{Solution Strategy}

In order to get good solutions to the design problem using the rigorous model (P1), we use the globally optimal solution of the simplified model (P2) to initialize the 
variables in the rigorous model. However, the global optimization of even the simplified NLP model (P2), that has a special structure in terms of the nonconvexities, is a very challenging task for medium to large-scale problems. Taking advantage of the fact that the model (P2) has a decomposable structure, we propose to globally optimize this model using a Lagrangean decomposition algorithm. This algorithm along with the technique to initialize the variables in the rigorous model is presented in this section.

\subsection{Global optimization of the simplified model}

We propose a Lagrangean decomposition based spatial branch and bound algorithm for solving the simplified model (P2) to global optimality. In this approach, we generate tight lower bounds on the global optimum using a decomposition technique. These lower bounds are then made to converge to the solution in a branch and bound setting.

\section{$\underline{4.1 .1 \text { Generation of tight relaxations }}$}

The technique to generate tight lower bounds on the global optimum of (P2) is based on the concept of Lagrangean decomposition. ${ }^{20}$ The basic idea of this solution methodology is to decompose the given large-scale problem into a collection of smaller, more tractable subproblems in order to obtain a lower bound on the solution of the initial problem. $^{21}$ This technique can be applied to models that can be decomposed into submodels with each submodel containing its separate set of variables. The simplified NLP model (P2) also has a decomposable structure and can be represented as follows: 


$$
\begin{array}{ll}
\min & \phi=\sum_{\mathrm{t} \in \mathrm{MOD}}\left(\mathrm{F}_{\mathrm{a}}^{\mathrm{t}}+4 \cdot \mathrm{F}_{\mathrm{g}}^{\mathrm{t}}\right) \\
\text { s.t } & \text { aqueous phase equations } \\
& \text { stripping phase equations } \\
& \text { coupling equation }
\end{array}
$$

The aqueous phase equations are the eqs (15), (17), (20), (22), (32), (33) and (36); the stripping phase equations consist of the eqs (16), (18), (21), (23), (25), (27) - (29) and (34), while eq (35) is the coupling equation that accounts for the transfer of the solute between the two phases. The coupling equation is the only equation apart from the objective function that contains variables common to both the aqueous phase equations and the stripping phase equations. These are known as the linking variables. In order to decompose the NLP problem (P2) into different subproblems, we first create duplicates of all the linking variables $\left\{F_{g}^{t}, F_{a}^{t}, C_{g}^{k^{\prime}}, C_{g}^{i^{\prime}}, C_{a}^{k} \quad\left(\forall t \in M O D, i^{\prime} \in t_{\text {out }}^{e}, k^{\prime} \in t_{\text {in }}^{e}, k \in t_{\text {in }}^{a}\right)\right\}$ appearing in the coupling equation (eq (35)) to get the following two sets of duplicate variables:

$$
\begin{aligned}
& \left\{\mathrm{F}_{\mathrm{g} 1}^{\mathrm{t}}, \mathrm{F}_{\mathrm{a} 1}^{\mathrm{t}}, \mathrm{C}_{\mathrm{g} 1}^{\mathrm{k}^{\prime}}, \mathrm{C}_{\mathrm{g} 1}^{\mathrm{i}^{\prime}}, \mathrm{C}_{\mathrm{a} 1}^{\mathrm{k}} \quad\left(\forall \mathrm{t} \in \text { MOD } \mathrm{i}^{\prime} \in \mathrm{t}_{\mathrm{out}}^{\mathrm{e}}, \mathrm{k}^{\prime} \in \mathrm{t}_{\mathrm{in}}^{\mathrm{e}}, \mathrm{k} \in \mathrm{t}_{\mathrm{in}}^{\mathrm{a}}\right)\right\} \\
& \left\{\mathrm{F}_{\mathrm{g} 2}^{\mathrm{t}}, \mathrm{F}_{\mathrm{a} 2}^{\mathrm{t}}, \mathrm{C}_{\mathrm{g} 2}^{\mathrm{k}^{\prime}}, \mathrm{C}_{\mathrm{g} 2}^{\mathrm{i}^{\prime}}, \mathrm{C}_{\mathrm{a} 2}^{\mathrm{k}} \quad\left(\forall \mathrm{t} \in \mathrm{MOD}, \mathrm{i}^{\prime} \in \mathrm{t}_{\mathrm{out}}^{\mathrm{e}}, \mathrm{k}^{\prime} \in \mathrm{t}_{\mathrm{in}}^{\mathrm{e}}, \mathrm{k} \in \mathrm{t}_{\mathrm{in}}^{\mathrm{a}}\right)\right\}
\end{aligned}
$$

We then replace the instances of the variables $\left\{F_{g}^{t}, F_{a}^{t}, C_{g}^{k}, C_{g}^{\prime}, C_{a}^{k} \quad\left(\forall t \in M O \not \supset \in t_{\text {oue }}^{e} k^{\prime} \in t_{i n}^{e}, k \in t_{i n}^{a}\right)\right\}$ occurring in the aqueous phase equations with the set of variables (A1), and their occurrences in the stripping phase equations, with the set of variables (A2). The coupling equation is also now re-written in terms of these newly introduced variables to get eqs (37) and (38).

$$
\mathrm{F}_{\mathrm{g} 1}^{\mathrm{t}} \cdot\left(\mathrm{C}_{\mathrm{g} 1}^{\mathrm{i}^{\prime}}-\mathrm{C}_{\mathrm{g} 1}^{\mathrm{k}^{\prime}}\right)=\mathrm{F}_{\mathrm{a} 1}^{\mathrm{t}} \cdot \mathrm{C}_{\mathrm{a} 1}^{\mathrm{k}} \cdot\left(1-\beta_{\mathrm{a}}\right) \cdot\left(1-\beta_{\mathrm{g}}\right) \quad \forall \mathrm{t} \in \mathrm{MOD}, \mathrm{i}^{\prime} \in \mathrm{t}_{\mathrm{out}}^{\mathrm{e}}, \mathrm{k}^{\prime} \in \mathrm{t}_{\mathrm{in}}^{\mathrm{e}}, \mathrm{k} \in \mathrm{t}_{\mathrm{in}}^{\mathrm{a}}
$$




$$
\mathrm{F}_{\mathrm{g} 2}^{\mathrm{t}} \cdot\left(\mathrm{C}_{\mathrm{g} 2}^{\mathrm{i}^{\prime}}-\mathrm{C}_{\mathrm{g} 2}^{\mathrm{k}^{\prime}}\right)=\mathrm{F}_{\mathrm{a} 2}^{\mathrm{t}} \cdot \mathrm{C}_{\mathrm{a} 2}^{\mathrm{k}} \cdot\left(1-\beta_{\mathrm{a}}\right) \cdot\left(1-\beta_{\mathrm{g}}\right) \quad \forall \mathrm{t} \in \mathrm{MOD}, \mathrm{i}^{\prime} \in \mathrm{t}_{\text {out }}^{\mathrm{e}}, \mathrm{k}^{\prime} \in \mathrm{t}_{\mathrm{in}}^{\mathrm{e}}, \mathrm{k} \in \mathrm{t}_{\mathrm{in}}^{\mathrm{a}}
$$

Further, the objective function is modified as follows:

$$
\min \phi=\sum_{t \in M O D}\left(F_{a 1}^{t}+4 \cdot F_{g 2}^{t}\right)
$$

Finally, since these newly formed variables are duplicates of the variables present in the original model, they are related by the following equality constraints, which are added to the model (P2).

$$
\begin{array}{ll}
\left(\mathrm{F}_{\mathrm{g} 1}^{\mathrm{t}}-\mathrm{F}_{\mathrm{g} 2}^{\mathrm{t}}\right)=0 & \forall \mathrm{t} \in \mathrm{MOD} \\
\left(\mathrm{F}_{\mathrm{a} 1}^{\mathrm{t}}-\mathrm{F}_{\mathrm{a} 2}^{\mathrm{t}}\right)=0 \quad \forall \mathrm{t} \in \mathrm{MOD} \\
\left(\mathrm{C}_{\mathrm{g} 1}^{\mathrm{k}^{\prime}}-\mathrm{C}_{\mathrm{g} 2}^{\mathrm{k}^{\prime}}\right)=0 \quad \forall \mathrm{t} \in \mathrm{MOD}, \mathrm{k}^{\prime} \in \mathrm{t}_{\mathrm{in}}^{\mathrm{e}} \\
\left(\mathrm{C}_{\mathrm{g} 1}^{\mathrm{i}^{\prime}}-\mathrm{C}_{\mathrm{g} 2}^{\mathrm{i}^{\prime}}\right)=0 \quad \forall \mathrm{t} \in \mathrm{MOD}, \mathrm{i}^{\prime} \in \mathrm{t}_{\mathrm{out}}^{\mathrm{e}} \\
\left(\mathrm{C}_{\mathrm{a} 1}^{\mathrm{k}}-\mathrm{C}_{\mathrm{a} 2}^{\mathrm{k}}\right)=0 \quad \forall \mathrm{t} \in \mathrm{MOD}, \mathrm{k} \in \mathrm{t}_{\mathrm{in}}^{\mathrm{a}}
\end{array}
$$

We then multiply the equations (40), (41), (42), (43) and (44) with parameters (Lagrange multipliers) $\lambda_{1}^{t}, \quad \lambda_{2}^{t}, \quad \lambda_{3}^{t, k^{\prime}}, \quad \lambda_{4}^{t, i^{\prime}}, \quad \lambda_{5}^{t, k} \quad\left(\forall t \in M O D, i^{\prime} \in t_{\text {out }}^{e}, k^{\prime} \in t_{\text {in }}^{e}, k \in t_{\text {in }}^{a}\right)$, respectively, and transfer these constraints to the objective function to get a Lagrangean relaxation of (P2), which is denoted by model (LRP) and is shown below:

$$
\begin{aligned}
& \min \phi^{L R P}=\sum_{t \in M O D}\left(\mathrm{~F}_{\mathrm{a} 1}^{\mathrm{t}}+4 \cdot \mathrm{F}_{\mathrm{g} 2}^{\mathrm{t}}\right)+\sum_{t \in M O D} \lambda_{1}^{\mathrm{t}} \cdot\left(F_{g 1}^{t}-F_{g 2}^{t}\right)+\sum_{t \in M O D} \lambda_{2}^{t} \cdot\left(F_{a 1}^{t}-F_{a 2}^{t}\right)+ \\
& \sum_{\substack{k^{\prime} \in t_{i n}^{e} \\
t \in M O D}} \lambda_{3}^{t^{\prime} k^{\prime}} \cdot\left(C_{g 1}^{k^{\prime}}-C_{g 2}^{k^{\prime}}\right)+\sum_{\substack{i^{\prime} \in \in \text { out } \\
t \in M O D}} \lambda_{4}^{t, i^{\prime}} \cdot\left(C_{g 1}^{i^{\prime}}-C_{g 2}^{i^{\prime}}\right)+\sum_{\substack{k \in t_{i n}^{a} \\
t \in M O D}} \lambda_{5}^{t, k} \cdot\left(C_{a 1}^{k}-C_{a 2}^{k}\right) \\
& \text { s.t aqueous phase equations involving }\left\{F_{g 1}^{t}, F_{a 1}^{t}, C_{g 1}^{k^{\prime}}, C_{g 1}^{i^{\prime}}, C_{a 1}^{k} \quad\left(\forall t \in M O D, i^{\prime} \in t_{o u}^{e}, k^{\prime} \in t_{i n}^{e}, k \in t_{i n}^{a}\right)\right\} \\
& \text { stripping phase equations involving }\left\{F_{g 2}^{t}, F_{a 2}^{t}, C_{g 2}^{k^{\prime}}, C_{g 2}^{i^{\prime}}, C_{a 2}^{k} \quad\left(\forall t \in M O D i^{\prime} \in t_{\text {out }}^{e}, k^{\prime} \in t_{\text {in }}^{e}, k \in t_{\text {in }}^{a}\right)\right\}
\end{aligned}
$$


For fixed values of the multipliers, this Lagrangean relaxation of (P2) can be decomposed into two subproblems (SP1) and (SP2) with model (SP1) pertaining to the aqueous phase and model (SP2) corresponding to the stripping phase.

$$
\begin{aligned}
& \min \phi_{1}=\sum_{t \in M O D} \mathrm{~F}_{\mathrm{a} 1}^{\mathrm{t}}+\sum_{t \in M O D} \lambda_{1}^{t} \cdot F_{g 1}^{t}+\sum_{t \in M O D} \lambda_{2}^{t} \cdot F_{a 1}^{t}+\sum_{\substack{k^{\prime} \in t_{i n}^{t} \\
t \in M O D}} \lambda_{3}^{t, k^{\prime}} \cdot C_{g 1}^{k^{\prime}}+\sum_{\substack{i^{\prime} \in t_{\text {out }}^{\mathrm{t}} \\
t \in M O D}} \lambda_{4}^{t_{1}^{\prime}} \cdot C_{g 1}^{i^{\prime}}+\sum_{\substack{k \in t_{i n}^{d} \\
t \in M O D}} \lambda_{5}^{t, k} \cdot C_{a 1}^{k} \\
& \text { s.t aqueous phase equations involving }\left\{F_{g 1}^{t}, F_{a 1}^{t}, C_{g 1}^{k^{\prime}}, C_{g 1}^{i^{\prime}}, C_{a 1}^{k} \quad\left(\forall t \in M O D, i^{\prime} \in t_{o u t}^{e}, k^{\prime} \in t_{i n}^{e}, k \in t_{i n}^{a}\right)\right\} \\
& \text { eq (37) }
\end{aligned}
$$

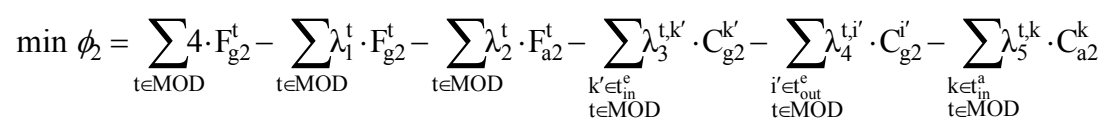

$$
\begin{aligned}
& \text { s.t stripping phase equations involving }\left\{F_{g 2}^{t}, F_{a 2}^{t}, C_{g 2}^{k^{\prime}}, C_{g 2}^{i^{\prime}}, C_{a 2}^{k} \quad\left(\forall t \in M O D i^{\prime} \in t_{\text {out }}^{e}, k^{\prime} \in t_{i n}^{e}, k \in t_{i n}^{a}\right)\right\} \\
& \text { eq (38) }
\end{aligned}
$$

Model (SP1) contains the variables (A1) and the variables corresponding to the aqueous phase while model (SP2) involves the variables (A2) and the variables pertaining to the stripping phase. It is to be noted that in these subproblems, the bounds of the duplicate variables are the same as the bounds of the variables $\left\{F_{g}^{t}, F_{a}^{t}, C_{g}^{k^{\prime}}, C_{g}^{i^{\prime}}, C_{a}^{k} \quad\left(\forall t \in M O D, i^{\prime} \in t_{\text {out }}^{e}, k^{\prime} \in t_{i n}^{e}, k \in t_{i n}^{a}\right)\right\}$ appearing in the original model (P2).

Each subproblem is then solved to global optimality to obtain solutions $\phi_{1}^{*}$ and $\phi_{2}^{*}$. These solutions are then added up to obtain a rigorous lower bound on the global optimum of model (P2) over a particular region of the feasible space. It is worth mentioning here that the values of the Lagrange multipliers can be updated using a subgradient method ${ }^{22}$ and the subproblems solved iteratively using the updated Lagrange multipliers to obtain tighter lower bounds. 


\subsubsection{Proposed global optimization algorithm}

The outline of the proposed global optimization algorithm is as follows:

Step 1. Preprocessing The bounds on the variables in the system are determined using the numerical data given for the treatment modules and the streams in the network. In this step, the non-convex NLP model (P2) is locally optimized to obtain an initial overall upper bound (OUB) on the objective function.

Step 2. Lower Bounding problem The procedure described in section 4.1.1 is used to obtain a lower bound (LB) at every node of the branch and bound tree.

Step 3. Upper Bound (UB) We solve the non-convex NLP model (P2) using a local NLP solver to obtain an upper bound at a node of the tree, and the OUB is updated if there is an improvement.

Step 4. Convergence A node in the spatial branch and bound tree is fathomed if either the lower bound at the node is greater than the current OUB or if the optimality gap between the lower bound and the overall upper bound is smaller than a certain tolerance. When there are no open nodes in the tree, the search procedure is stopped.

Step 5. Spatial Branch and Bound Regions of the search space for which the relaxation gap between the lower bounds and the overall upper bound is greater than the specified tolerance are further partitioned into disjoint sub-regions to create new nodes in the tree, and steps 2-4 are repeated for each of these regions. Certain heuristics similar to the ones used by Caroe and Schultz ${ }^{23}$ are used as the branching rules in this work. The branching is performed on the linking variables. A linking variable usually takes on different values in the solutions of the subproblems (SP1) and (SP2), which are given by the optimal 
values of the duplicate variables appearing in these subproblems pertaining to that certain linking variable. For all the linking variables, the absolute value of the difference of the values of the corresponding duplicate variables is computed. The linking variable for which this difference is maximum is chosen as the branching variable. Finally, we select the mid-point of the optimal values of the duplicate variables (as obtained from the solutions of (SP1) and (SP2) ) corresponding to the chosen linking variable as the branching point. Theoretically, the spatial branch and bound is an infinite process since the branching is done on the continuous variables, but terminates in a finite number of nodes for $\varepsilon$-convergence.

\subsection{Initialization of variables in the rigorous model}

The globally optimal solution of the simplified problem is used as a starting point for solving the rigorous NLP model (P1). We assume that all the streams with zero flowrates in the solution of the simplified model also do not exist in the optimal network. Therefore, all the flows that are zero in the simplified model are set to zero in the rigorous model. We then obtain a local optimum for the reduced rigorous model by optimizing this model with a local NLP solver.

\section{Examples}

The proposed method has been applied to the optimization of emulsion pertraction processes, which are used for the removal and recovery of anionic pollutants from polluted groundwater. The particular case study considered in this work involves the removal of anionic hexavalent chromium $\left(\mathrm{HCrO}_{4}^{-}\right)$from polluted groundwater. In order to determine the optimal number of membrane modules for groundwater remediation, three cases were considered: (a) a network with two modules, (b) a network 
with three modules and (c) a network with four modules. All the cases were formulated using $\mathrm{GAMS}^{24}$ and solved on a $1400-\mathrm{MHz}$ AMD K7 Windows machine with $512 \mathrm{MB}$ memory. GAMS/CONOPT 3.0 was used to get local solutions to the NLP problems, while GAMS/BARON 7.2.5 $5^{25}$ was used to solve the subproblems (SP1) and (SP2), derived from the simplified model (P2), to global optimality.

Test problem: The incoming groundwater stream has a known flowrate, $F_{a}^{\text {in }}=2.5 \mathrm{~m}^{3} \mathrm{~h}^{-1}$ and a known concentration of chromium, $C_{a}^{i n}=7.7 \mathrm{~mol} \mathrm{~m}^{-3}(400 \mathrm{ppm})$ (present in the form of $\mathrm{HCrO}_{4}^{-}$). The $\mathrm{pH}$ of the aqueous feed solution is 1.5. An upper bound on the concentration of the pollutant in the aqueous discharge stream is imposed by environmental regulations as $C_{a}^{\text {out }} \leq 0.00961 \mathrm{~mol} \mathrm{~m}^{-3}(0.5 \mathrm{ppm})$. The concentration of the pollutant in the stripping phase in the outlet stream from the decanting tank has to be greater than a certain amount, that is, $C_{g}^{\text {out }}$ should be greater than $380 \mathrm{~mol} \mathrm{~m}^{-3}(\sim 20000$ ppm) in order to reuse the contaminant rich stripping phase in other processes. Further, an analysis of the experimental data allows the average values of the extraction and back extraction percentages to be calculated, which are required for solving the simplified model. For all the cases, the values of the $\beta_{a}$ and $\beta_{g}$ are taken as 0.05 and 0.3 , respectively, for all the treatment modules. Further, we arbitrarily choose an initial value of $10^{-5}$ for the Lagrange multipliers for solving the subproblems of the simplified model (P2), in all the cases.

The data used for the rigorous model is essentially the same as that used in the simplified model. Furthermore, for the rigorous model we require additional information which follows. The volume ratio between the extractant (Alamine 336) and the stripping 
solution (sodium hydroxide solution) is $1: 4{ }^{8}$ The values of the model parameters that are used to solve the problem are given in Table 1.

Table 1. Model Parameters.

\begin{tabular}{|c|c|c|}
\hline Parameter & Value & Units \\
\hline $\mathrm{K}_{\mathrm{eq}}$ & 4.83 & $\mathrm{~mol}^{-2} \mathrm{~m}^{6}$ \\
\hline $\mathrm{K}_{\mathrm{L}}=\mathrm{K}_{\mathrm{LH}}$ & 0.025 & $\mathrm{~m} \mathrm{~h}^{-1}$ \\
\hline $\mathrm{K}_{\mathrm{M}}$ & $1.17 \times 10^{-3}$ & $\mathrm{~m} \mathrm{~h}^{-1}$ \\
\hline $\mathrm{K}_{\mathrm{o}} \cdot \mathrm{A}_{\mathrm{v}}$ & $2.94 \times 10^{4}$ & $\mathrm{~h}^{-1}$ \\
\hline
\end{tabular}

The value of $K_{e q}$ was experimentally obtained, while the value of $K_{L}$ was calculated using correlations. $K_{M}$ and $K_{o} \cdot A_{v}$ are obtained by means of parameter estimation using the estimation tool gEST from gPROMS. Finally, the length of the axial dimension of each membrane module is discretized by dividing the membrane length into ten intervals and thus $\mathrm{N}=10$, in all the cases.

Case a. The first case is a very small problem that involves the design of a groundwater remediation network with two membrane modules. Figures 6 and 7 show the proposed network superstructures for the aqueous phase and the emulsion phase, respectively, for this case. 


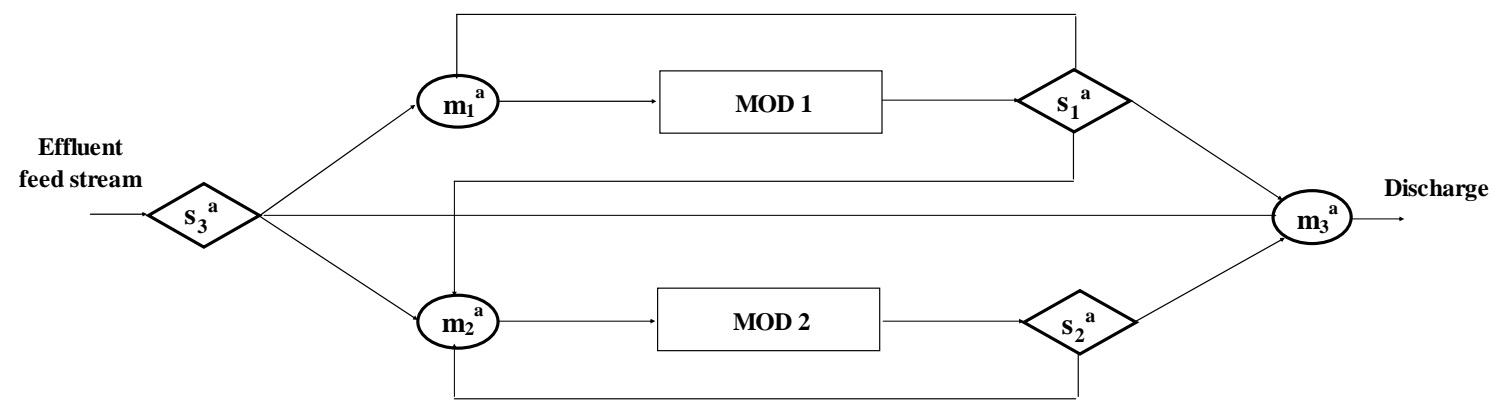

Figure 6. Case a: Network superstructure for the aqueous feed solution.

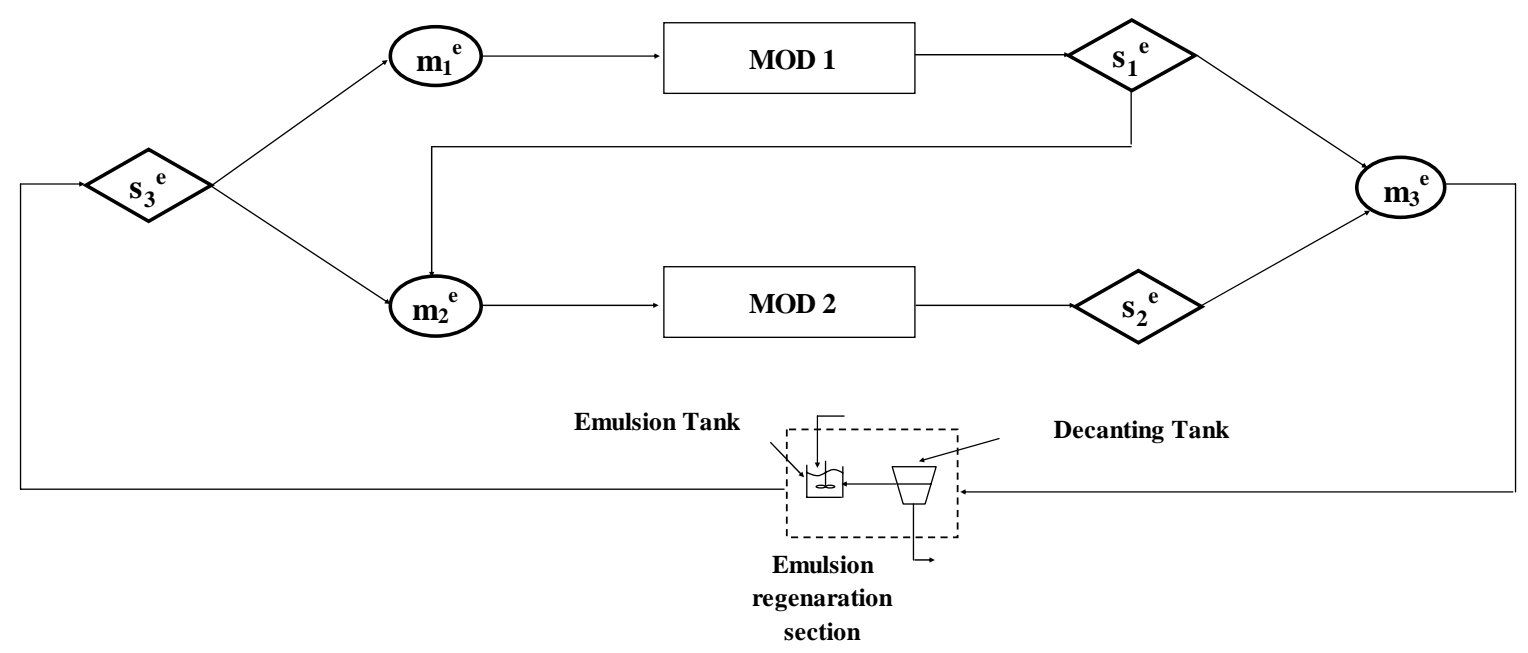

Figure 7. Case a: Network superstructure for the emulsion phase.

The simplified NLP model (P2) for this example involves 65 variables and 58 constraints. Initially, we attempted to solve the simplified model using BARON. It is found that there is no feasible solution to the problem and the required discharge restriction on the contaminant concentration cannot be met by just using two treatment modules with $\beta_{a}=0.05$ and $\beta_{g}=0.3$. The lowest possible contaminant concentration in the aqueous stream discharge that is attainable using two membrane modules with $\beta_{a}=$ 0.05 and $\beta_{g}=0.3$ is $0.0193 \mathrm{~mol} \mathrm{~m}^{-3}$. 
We then try to solve the rigorous NLP model (P1) pertaining to this case (with 252 variables and 248 constraints) and find that the problem is still infeasible. On relaxing the contaminant discharge concentration and globally optimizing the rigorous model using BARON, we do get feasible structures (shown in Fig. 8 and Fig. 9) although the aqueous stream has a higher contaminant discharge.

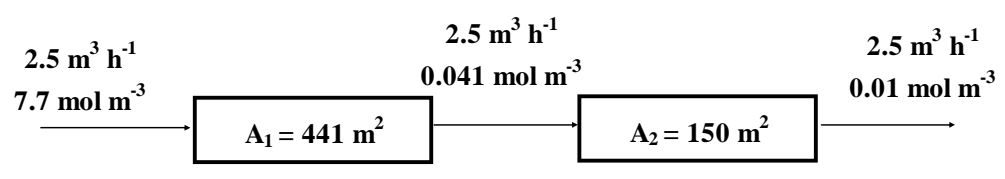

Figure 8. Case a: Rigorous model solution (relaxed discharge concentration limits) -

Optimal network structure for the aqueous stream.

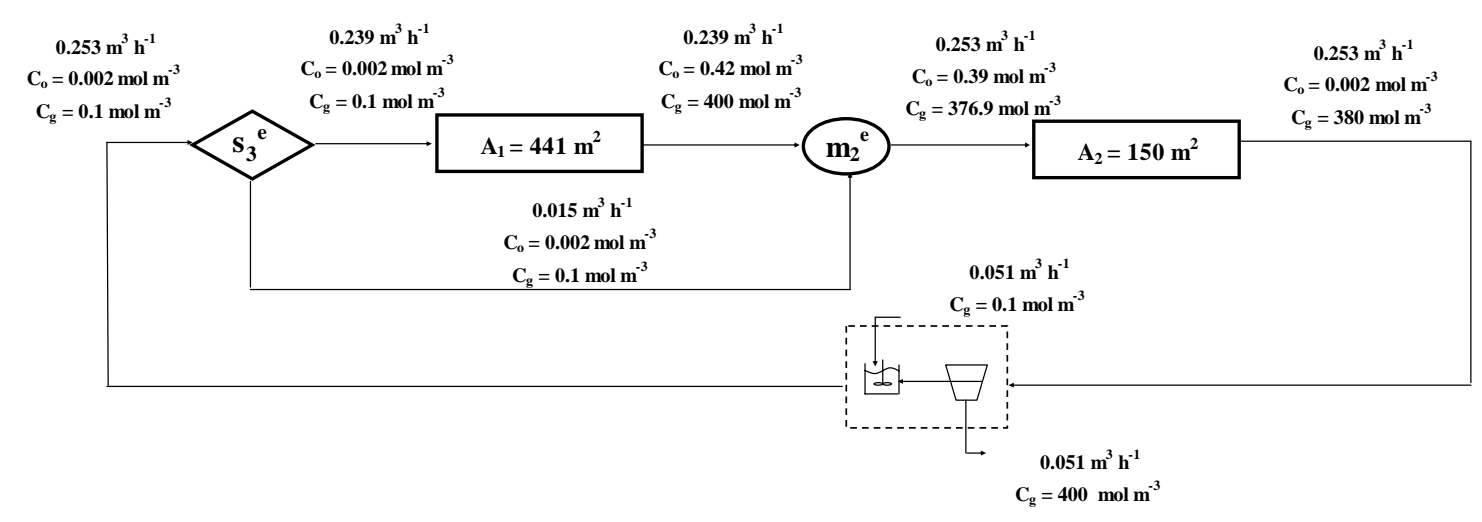

Figure 9. Case a: Rigorous model solution (relaxed discharge concentration limits) -

Optimal solution for the emulsion phase network.

$\underline{\text { Case } b}$. The second case involves the design of an groundwater remediation network with three membrane modules. Through this case we want to determine if three membrane modules can perform the required levels of treatment of the given groundwater stream 
and also yield a contaminant rich side stream with a specified concentration of the contaminant. The network superstructures are shown in Figures 10 and 11.

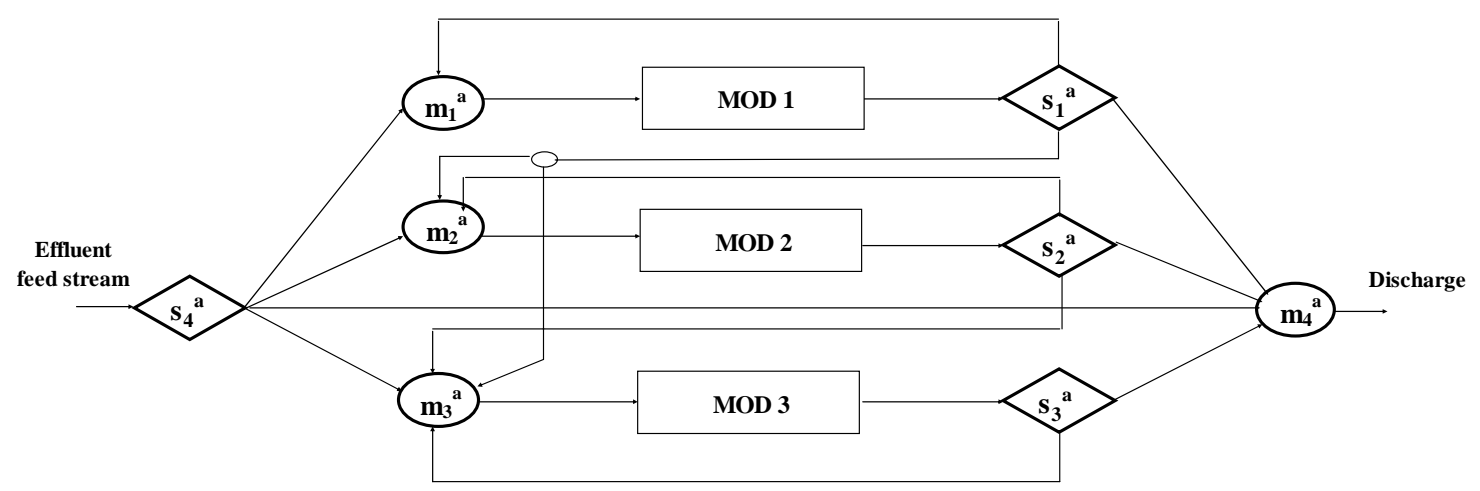

Figure 10. Case b: Network superstructure for the aqueous feed solution.

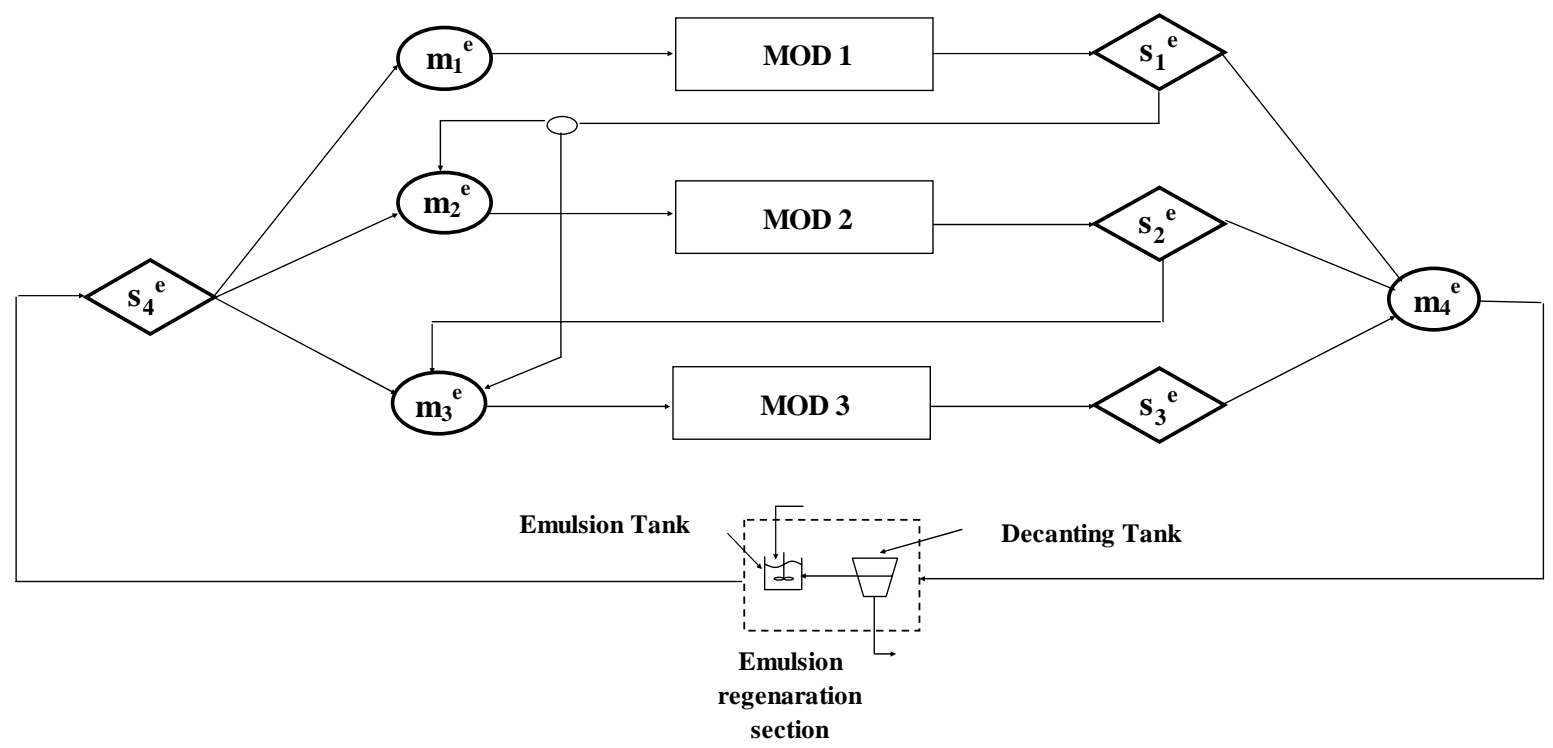

Figure 11. Case b: Network superstructure for the emulsion phase.

The simplified NLP model (P2) for this case involves 97 variables and 83 constraints. Initially, the simplified model was solved using BARON which gave a 
solution of $6.56 \mathrm{~m}^{3} \mathrm{~h}^{-1}$ with $1 \%$ tolerance for the gap between the lower bound and the global optimum. The computational time taken to solve the model was 20.81 CPUsecs.

We apply the proposed algorithm to this case, where we solve the subproblems (SP1) and (SP2) to global optimality with $1 \%$ tolerance for the gap between the lower bounds and the global optimum. Using the solutions of these subproblems, we get a rigorous lower bound of $6.54 \mathrm{~m}^{3} \mathrm{~h}^{-1}$ on the global optimum. Further, an upper bound of $6.56 \mathrm{~m}^{3} \mathrm{~h}^{-1}$ is obtained by locally optimizing model (P2) with CONOPT 3.0. The lower bound obtained above, is within $0.4 \%$ of the upper bound and therefore this solution is globally optimal for a specified tolerance of $0.4 \%$. The search for the global optimum was stopped at the root node of the tree. The proposed algorithm takes a total time of 2.08 CPUsecs to solve, which is still less than the time taken by BARON to optimize model (P2). Figures 12 and 13 show the globally optimal network configurations for the aqueous phase and the emulsion phase, respectively. The flowrates and the contaminant concentrations of the streams in the network are also shown in these figures.

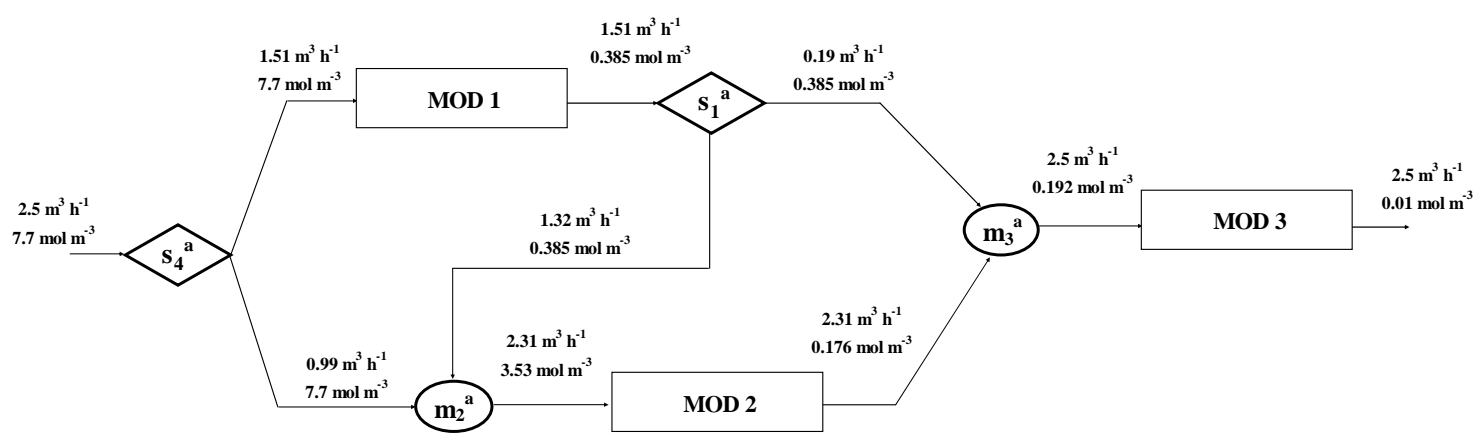

Figure 12. Case b: Globally optimal network structure for the aqueous solution using simplified model. 


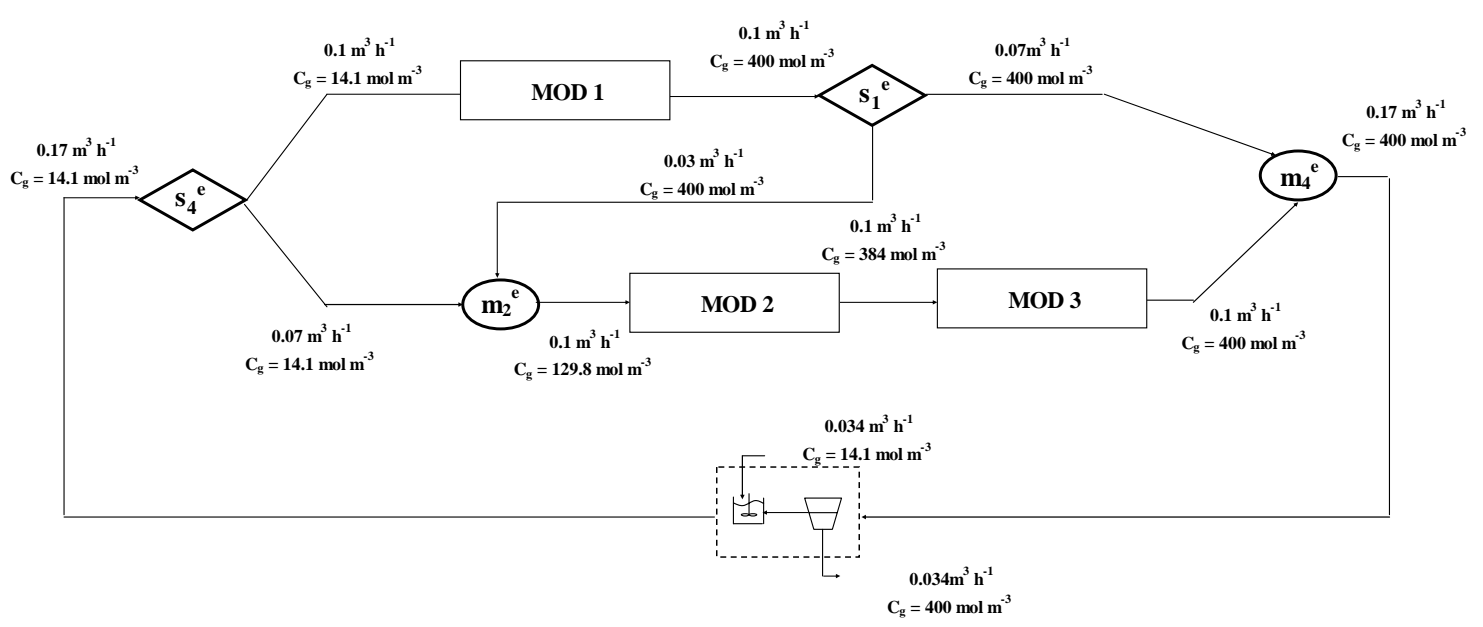

Figure 13. Case b: Globally optimal solution for the emulsion phase using simplified model.

Figure 12 shows that two stages are necessary to satisfy the constraints for the aqueous solution. Modules 1 and 2 are used to remove most of the pollutant, while modules 3 works as purification units. For the emulsion phase, the flowrates and chromium concentration in the stripping phase are shown in Figure 13.

We analyze the optimal network structures obtained by solving the simplified model, and the flowrates that are found to be zero in the solution of the simplified model, are set to zero in the rigorous model. The values of the other flows and the concentrations in the simplified model are used as initial points to obtain the optimal solution of the rigorous NLP model (P1) that involves 380 variables and 370 constraints. The rigorous model (P1) is locally optimized using CONOPT 3.0 using the solution of the simplified model as a starting point, and it takes $0.171 \mathrm{CPU}$ secs to solve the problem. We obtain an objective function value of 591 where the main contribution to this value is from the membrane areas of the hollow fiber modules. The optimal configurations for the aqueous and the emulsion phases are shown in Figures 14 and 15, respectively. 


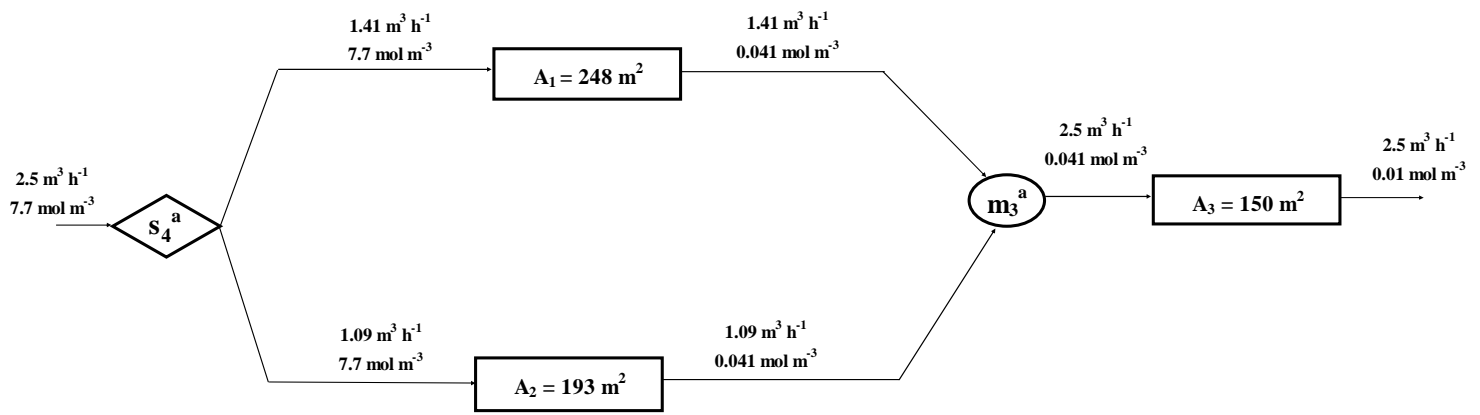

Figure 14. Case b: Rigorous model solution - Optimal network structure for the aqueous stream.

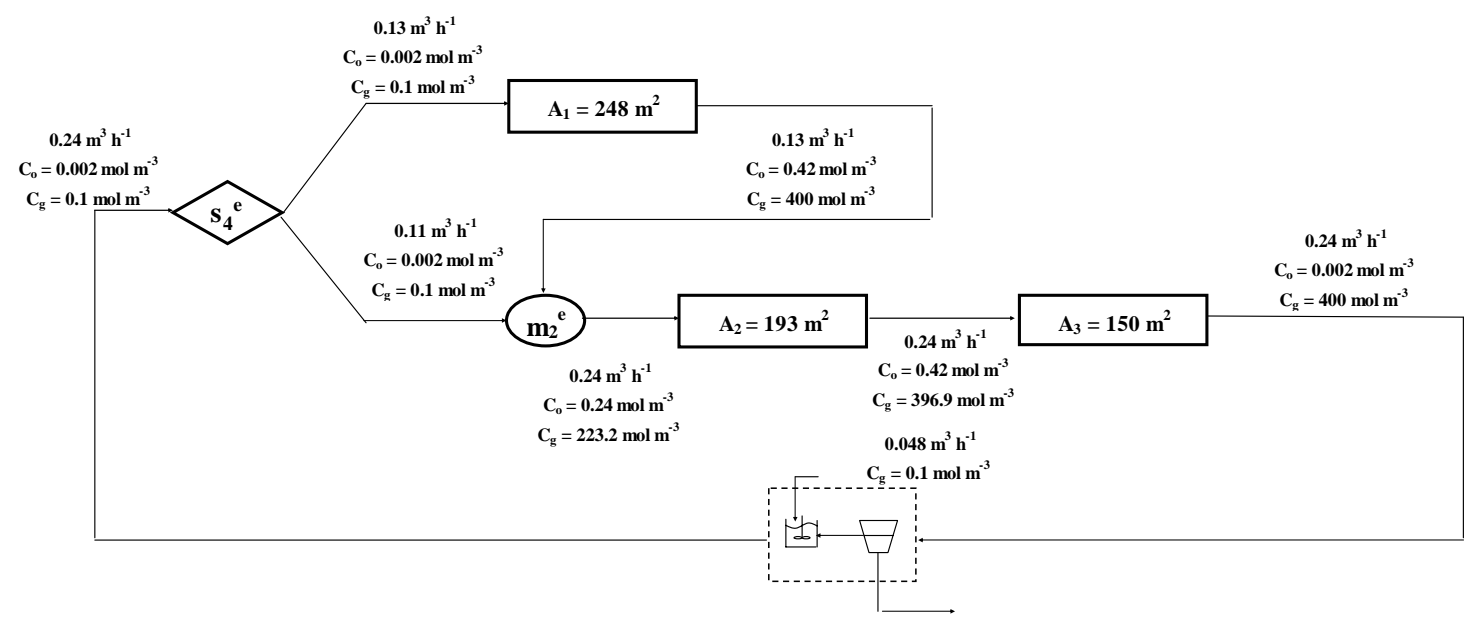

Figure 15. Case b: Rigorous model solution - Optimal solution for the emulsion phase network.

The optimal network structure obtained for the aqueous stream (Figure 14) is again a combination of a series and parallel flowsheet. Two modules are used to remove most of the pollutant for the groundwater stream, while the last one is used to remove the traces of the contaminant. For the emulsion phase, the network has a largely series structure as can be seen from Figure 15. 
In order to compare the solutions obtained from the rigorous and the simplified models, the sum of the aqueous phase flowrate and the organic phase flowrate inside the hollow fiber modules, which is the objective function in the simplified model, is calculated from the solution of the rigorous model. This sum is found to be $5.49 \mathrm{~m}^{3} \mathrm{~h}^{-1}$, which is close to the value of $6.56 \mathrm{~m}^{3} \mathrm{~h}^{-1}$ obtained from the simplified model. Therefore, the simplified model can be considered to be a close approximation of the rigorous model.

The network with these three treatment modules (with given removal ratios) can at best reduce the contaminant concentration in the aqueous discharge stream to 0.00096 mol m $\mathrm{m}^{-3}$. For a lower contaminant discharge limit, at least four membrane modules would be required. In the next case, we consider the case with four treatment modules to check if any cost advantages are obtained in using four modules instead of three for treating the given effluent stream.

Case . In the final test case, we optimize a groundwater remediation network consisting of four treatment unit modules. Figures 1 and 2 show the network superstructures for the aqueous phase and the emulsion phase, respectively, for this example. The simplified NLP model (P2) corresponding to this example system involves 133 variables and 110 constraints. On directly using BARON to solve the problem it was found that the solver could not prove global optimality of the solution it found in more than 10 hours. Applying the proposed algorithm to solve the problem, we first obtain a rigorous lower bound on the global optimum using the decomposition technique described in section 4.1.1. Here, we solve the subproblems (SP1) and (SP2) to global optimality with $2 \%$ tolerance for the gap between the lower bounds and the global optimum. From the 
solution of each of these subproblems, we take the tightest valid lower bounds on the global optima of these subproblems and add them to get a rigorous lower bound of $6.48 \mathrm{~m}^{3} \mathrm{~h}^{-1}$ on the global optimum of model (P2) for this example. Further, an upper bound of $6.64 \mathrm{~m}^{3} \mathrm{~h}^{-1}$ is obtained by locally optimizing model (P2) with CONOPT 3.0. The relaxation gap between this upper bound and the lower bound found earlier, is less than $2.5 \%$ of the upper bound and so this solution is globally optimal within a tolerance of 2.5\%. As in the previous case, no further branching was carried out. The proposed algorithm takes a total time of $611.07 \mathrm{CPUsecs}$ to solve, which is drastically less than the time taken by BARON to optimize model (P2).

Figures 16 and 17 show the globally optimal network configurations for the aqueous phase and the emulsion phase, respectively. The flowrates and the contaminant concentrations of the streams in the system are also shown in these figures.

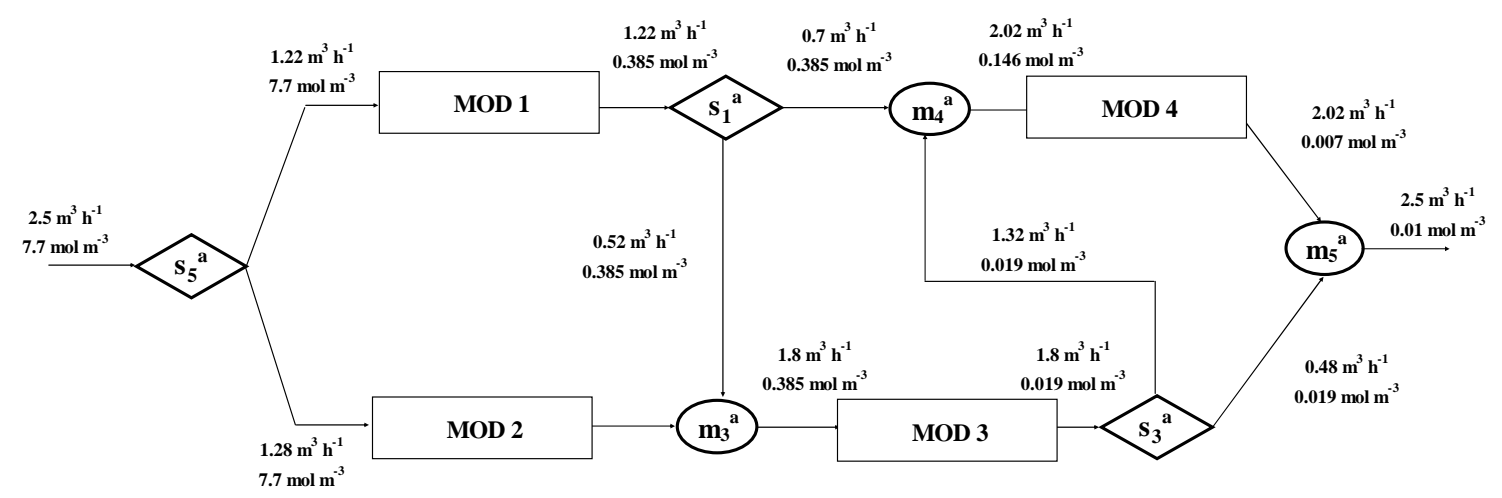

Figure 16. Case c: Globally optimal network structure for the aqueous solution using simplified model. 


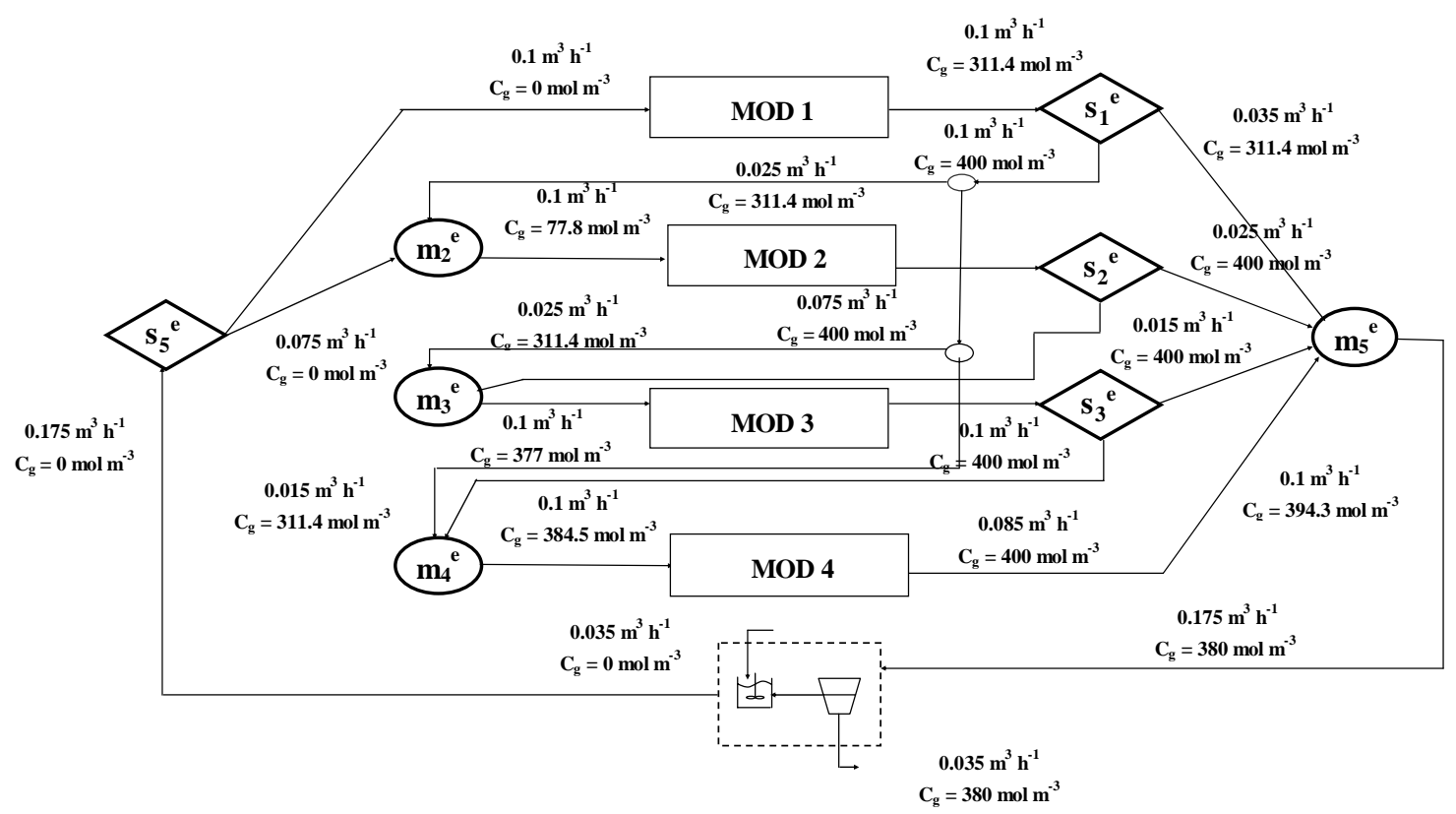

Figure 17. Case c: Globally optimal solution for the emulsion phase using simplified model.

We now use the solution of the simplified model (P2) as a starting point to solve the rigorous model (P1) which involves 517 variables and 498 constraints. On locally optimizing model (P1) corresponding to this example using CONOPT 3.0, it takes 0.046 CPUsecs to solve the problem and an objective function value of 624 is obtained. Figures 18 and 19 show the optimal configurations for the aqueous and the emulsion phases, respectively. 


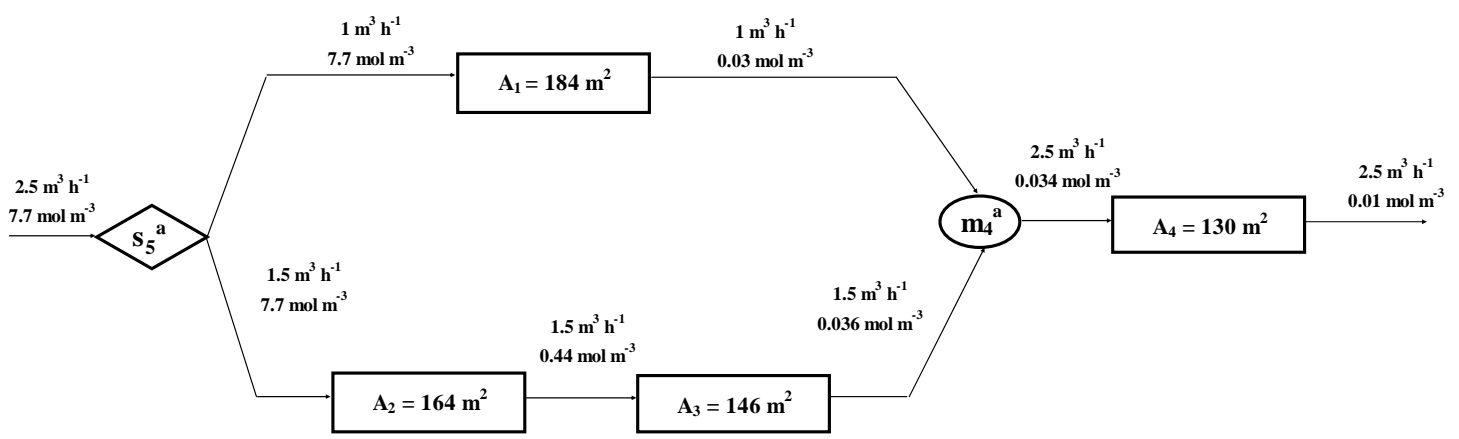

Figure 18. Case c: Optimal network structure for the aqueous stream obtained by solving the rigorous model.

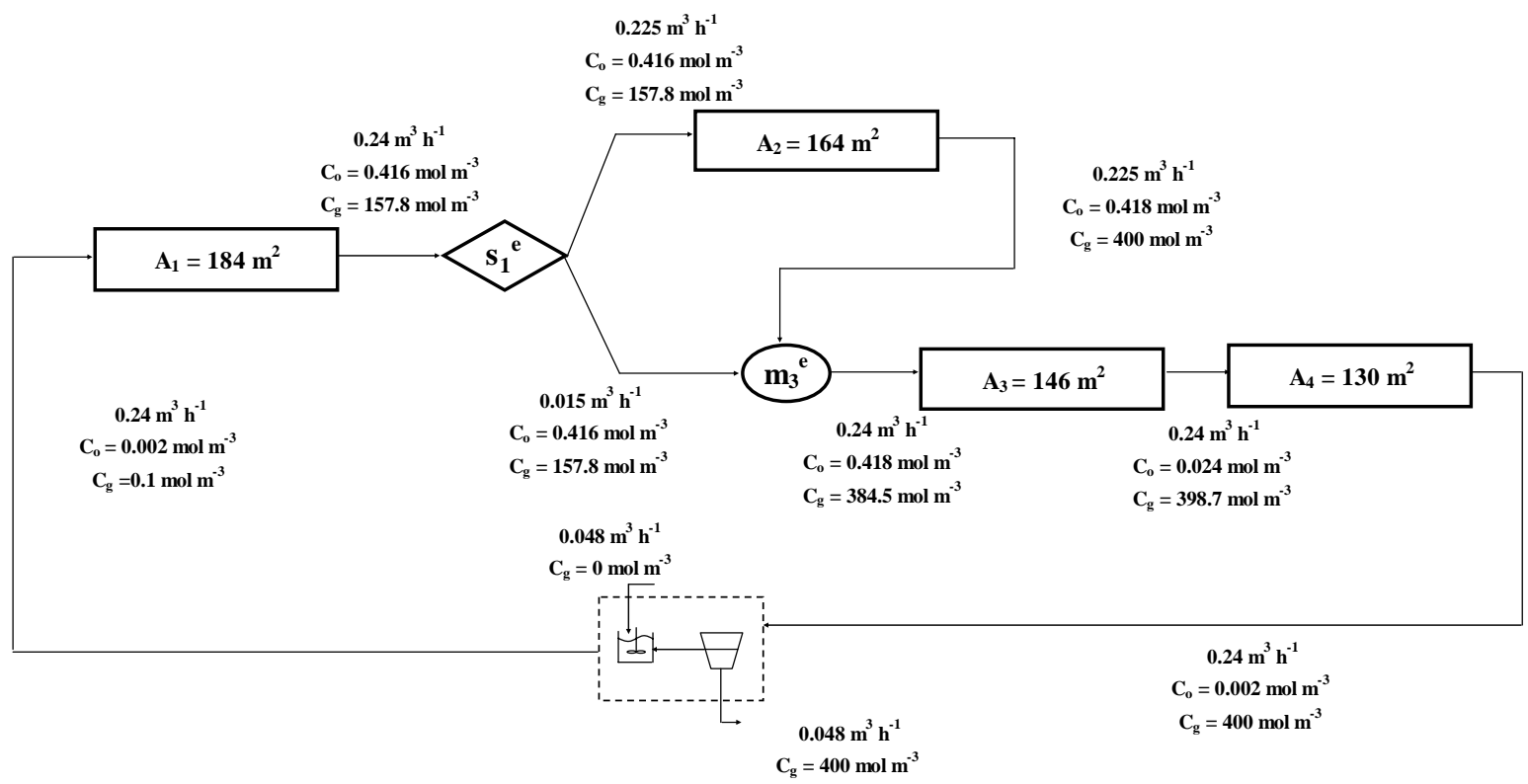

Figure 19. Case c: Optimal solution for the emulsion phase network obtained by solving the rigorous model.

It should be noted here that the flowrates of the emulsion phase are small due to the high concentration of chromium required in the stripping phase at the outlet of the decanting tank . 
It can be inferred from the above results that at least three membrane modules are required for treating the given polluted groundwater stream to the required levels. We may be able to use only two treatment modules if the contaminant recoveries are higher for the membrane modules.

From the computational results for all three cases, we can conclude that the cases with two and three membrane modules are small enough so that even the rigorous NLP model corresponding to these cases can be globally optimized using the commercial solver BARON in reasonable time. However, for getting lower discharge concentrations we need a higher number of treatment modules ( $>=4$ modules). As the problem size grows bigger, even getting a good locally optimal solution is not a trivial task and requires good starting points which can be obtained by solving a simplified model to global optimality. The failure of existing solvers to get a globally optimal solution of the simplified model requires the application of the proposed algorithm which makes use of the decomposable nature of the models. It is found that the proposed algorithm performs better than BARON in these case studies. In this work, when applying the proposed algorithm, we stop at the root node and do not continue with further branching since our aim is to get a good starting point for the rigorous model. So only steps 1 to 4 in the proposed algorithm are carried out when solving the test cases. 


\section{Conclusions}

We have presented in this paper a superstructure optimization approach for designing minimum cost groundwater remediation networks that permit the selective separation and recovery of anionic pollutants using membrane based solvent extraction technology. Initially, the optimization of the network superstructure is formulated as a nonconvex nonlinear programming problem making use of differential and algebraic equations. This rigorous NLP model which is highly nonconvex is then simplified using some assumptions to get a simplified NLP model. We propose a Lagrangean decomposition algorithm to solve this simplified model to global optimality where this model is decomposed into two sub-problems which are solved to global optimality and their solutions used to obtain a rigorous lower bound on the global optimum of this simplified model. Further, an upper bound is obtained by locally optimizing the simplified model. The globally optimal solution of the simplified model is used to initialize the rigorous NLP problem.

Numerical results of the application of the proposed algorithm on three cases involving different numbers of membrane modules (2, 3 and 4 modules) show that the proposed algorithm works better than the commercial solver BARON for medium to large-scale problems. The use of the heuristic developed to solve the rigorous NLP model provides us with optimal solutions to the design problem, and we find that we can meet the concentration specifications in the outlet streams using a remediation network with 3 treatment modules. 


\section{Acknowledgments}

Financial support from project BQU 2002-03357 (MEyC, Spain) is gratefully acknowledged. One of the authors (E. Bringas) is indebted to the Spanish Ministry of Education and Science for the research fellowship.

\section{Nomenclature}

Sets

$\mathrm{m}_{\mathrm{in}}^{\mathrm{a}} \quad$ Set of aqueous inlet streams into mixer $m^{a}$

$\mathrm{m}_{\text {in }}^{\mathrm{e}} \quad$ Set of emulsion inlet streams into mixer $m^{e}$

$\mathrm{m}_{\text {out }}^{\mathrm{a}} \quad$ Aqueous outlet stream from mixer $m^{a}$

$\mathrm{m}_{\text {out }}^{\mathrm{e}} \quad$ Emulsion outlet stream from mixer $m^{e}$

MOD Set of membrane modules

$\mathrm{MU}^{\mathrm{a}}$ Set of mixers for aqueous stream network

$\mathrm{MU}^{\mathrm{e}} \quad$ Set of mixers for emulsion stream network

$\mathrm{s}_{\text {in }}^{\mathrm{a}} \quad$ Aqueous inlet stream into splitter $s^{a}$

$\mathrm{s}_{\text {in }}^{\mathrm{e}} \quad$ Emulsion inlet stream into splitter $s^{e}$

$\mathrm{s}_{\text {out }}^{\mathrm{a}} \quad$ Set of aqueous outlet streams from splitter $s^{a}$

$\mathrm{s}_{\text {out }}^{\mathrm{e}} \quad$ Set of emulsion outlet streams from splitter $s^{e}$

$\mathrm{SU}^{\mathrm{a}} \quad$ Set of splitters for aqueous stream network

$\mathrm{SU}^{\mathrm{e}} \quad$ Set of splitters for emulsion stream network

$\mathrm{t}_{\text {in }}^{\mathrm{a}} \quad$ Aqueous stream inlet for membrane module $t$

$\mathrm{t}_{\text {in }}^{\mathrm{e}} \quad$ Emulsion stream inlet for membrane module $t$

$\mathrm{t}_{\text {out }}^{\mathrm{a}} \quad$ Aqueous stream outlet from membrane module $t$

$\mathrm{t}_{\text {out }}^{\mathrm{e}} \quad$ Emulsion stream outlet from membrane module $t$ 


\section{Subscripts}

$\begin{array}{ll}\mathrm{a} & \text { Aqueous phase } \\ \mathrm{g} & \text { Stripping phase } \\ \mathrm{i}, \mathrm{i}^{\prime}, \mathrm{k}, \mathrm{k}^{\prime} & \text { Stream indices } \\ \mathrm{o} & \text { Organic Phase } \\ \mathrm{p} & \text { Phases in the emulsion stream } \\ \mathrm{t} & \text { Modules }\end{array}$

\section{Variables}

$\mathrm{A}_{\mathrm{t}} \quad$ Membrane area of the module ' $\mathrm{t}$ ', $\mathrm{m}^{2}$

$\mathrm{A}_{\mathrm{v}} \quad$ Interfacial area of the stripping bubbles divided by the volume of the stripping phase, $\mathrm{m}^{2} / \mathrm{m}^{3}$

$C_{a}^{i} \quad$ Solute concentration in the aqueous stream ' $\mathrm{i}$ ', $\mathrm{m}^{3} \mathrm{~h}^{-1}$

$\mathrm{C}_{\mathrm{a}}^{\mathrm{in}} \quad$ Solute concentration in the effluent stream at the inlet of the aqueous network superstructure, $\mathrm{mol} \mathrm{m}^{-3}$

$\mathrm{C}_{\mathrm{a}}^{\text {out }} \quad$ Solute concentration in the aqueous discharge stream at the outlet of the aqueous network superstructure, $\mathrm{mol} \mathrm{m}^{-3}$

$\mathrm{C}_{\mathrm{a}}^{\mathrm{t}} \quad$ Bulk concentration of solute in the aqueous phase inside module ' $\mathrm{t}$ ', mol m${ }^{-3}$

$\mathrm{C}_{\mathrm{a}}^{\mathrm{t}^{*}} \quad$ Solute equilibrium concentration at the interface of the aqueous phase and the membrane in module ' $\mathrm{t}$ ', $\mathrm{mol} \mathrm{m}^{-3}$

$\mathrm{C}_{\mathrm{aH}}^{\mathrm{i}} \quad$ Concentration of hydrogen ions in aqueous stream ' $\mathrm{i}$ ', $\mathrm{m}^{3} \mathrm{~h}^{-1}$

$\mathrm{C}_{\mathrm{aH}}^{\mathrm{t}} \quad$ Bulk concentration of hydrogen ions in the aqueous phase inside module ' $\mathrm{t}$ ', mol $\mathrm{m}^{-3}$

$\mathrm{C}_{\mathrm{aH}}^{\mathrm{t}^{*}} \quad$ Equilibrium concentration of hydrogen ions at the interface of the aqueous phase and membrane in module ' $\mathrm{t}$ ', $\mathrm{mol} \mathrm{\textrm {m } ^ { - 3 }}$

$\mathrm{C}_{\mathrm{FE}}^{\mathrm{t}^{*}} \quad$ Equilibrium concentration of free extractant at the interface of the aqueous phase and the membrane in module ' $\mathrm{t}$ ', $\mathrm{mol} \mathrm{m}^{-3}$ 
$\mathrm{C}^{\mathrm{g}_{\text {in }}} \quad$ Solute concentration in the contaminant lean stripping stream inlet into the emulsion tank, mol m

$\mathrm{C}^{\mathrm{g}_{\text {out }}} \quad$ Solute concentration in the contaminant rich stripping stream at the outlet of the decanting tank, mol $\mathrm{m}^{-3}$

$\mathrm{C}_{\mathrm{g}}^{\mathrm{t}} \quad$ Bulk concentration of solute in the stripping phase inside module ' $\mathrm{t}$ ', $\mathrm{mol} \mathrm{m}^{-3}$

$\mathrm{C}_{\mathrm{o}}^{\mathrm{t}} \quad$ Bulk concentration of solute in the organic phase inside module ' $\mathrm{t}$ ', mol m $\mathrm{m}^{-3}$

$\mathrm{C}_{\mathrm{o}}^{\mathrm{t}^{*}} \quad$ Equilibrium concentration of solute in the organic phase at the membrane interface in module ' $\mathrm{t}$ ', $\mathrm{mol} \mathrm{m} \mathrm{m}^{-3}$

$C_{p}^{i} \quad$ Solute concentration in the phase ' $\mathrm{p}$ ' in stream ' $\mathrm{i}$ ', $\mathrm{m}^{3} \mathrm{~h}^{-1}$

$\mathrm{C}_{\mathrm{p}}^{\mathrm{r}_{\mathrm{in}}} \quad$ Solute concentration in the phase ' $\mathrm{p}$ ' in the inlet stream ' $\mathrm{r}_{\mathrm{in}}$ ' to the emulsion regeneration section, $\mathrm{mol} \mathrm{m} \mathrm{m}^{-3}$

$\mathrm{C}_{\mathrm{p}}^{\mathrm{r}_{\text {out }}} \quad$ Solute concentration in the phase ' $\mathrm{p}$ ' in the outlet stream ' $\mathrm{r}_{\text {out }}$ ' from the emulsion regeneration section, $\mathrm{mol} \mathrm{m}^{-3}$

$\mathrm{F}_{\mathrm{a}}^{\mathrm{i}} \quad$ Flowrate of the aqueous stream ' $\mathrm{i}$ ', $\mathrm{m}^{3} \mathrm{~h}^{-1}$

$\mathrm{F}_{\mathrm{p}}^{\mathrm{i}} \quad$ Flowrate of the phase ' $\mathrm{p}$ ' in the emulsion stream ' $\mathrm{i}$ ', $\mathrm{m}^{3} \mathrm{~h}^{-1}$

$\mathrm{F}^{\mathrm{g}_{\text {in }}} \quad$ Flowrate of the contaminant lean stripping stream inlet to the emulsion tank, $\mathrm{m}^{3} \mathrm{~h}^{-1}$

$\mathrm{F}^{\mathrm{g}_{\text {out }}} \quad$ Flowrate of the stripping stream at the outlet of the decanting tank, $\mathrm{m}^{3} \mathrm{~h}^{-1}$

$\mathrm{F}_{\mathrm{a}}^{\mathrm{t}} \quad$ Flowrate of the aqueous phase inside module ' $\mathrm{t}$ ', $\mathrm{m}^{3} \mathrm{~h}^{-1}$

$\mathrm{F}_{\mathrm{p}}^{\mathrm{t}} \quad$ Flowrate of the phase ' $\mathrm{p}$ ' inside module ' $\mathrm{t}$ ', $\mathrm{m}^{3} \mathrm{~h}^{-1}$

$\mathrm{F}_{\mathrm{p}}^{\mathrm{r}_{\mathrm{in}}} \quad$ Flowrate of the phase ' $\mathrm{p}$ ' in the inlet stream ' $\mathrm{r}_{\mathrm{in}}$ ' to the emulsion regeneration section, $\mathrm{m}^{3} \mathrm{~h}^{-1}$

$\mathrm{F}_{\mathrm{p}}^{\mathrm{r}_{\text {out }}} \quad$ Flowrate of the phase ' $\mathrm{p}$ ' at the outlet stream ' $\mathrm{r}_{\text {out }}$ ' from the emulsion regeneration section, $\mathrm{m}^{3} \mathrm{~h}^{-1}$

$\mathrm{J}_{\mathrm{a}}^{\mathrm{t}}$ Mass transfer flux in the aqueous phase stagnant layer inside module ' $\mathrm{t}$ ', mol m $\mathrm{m}^{-2}$ $\mathrm{h}^{-1}$ 
$\mathrm{J}_{\mathrm{p}}^{\mathrm{t}} \quad$ Mass transfer flux in phase ' $\mathrm{p}$ ' inside module ' $\mathrm{t}$ ', $\mathrm{mol} \mathrm{m} \mathrm{m}^{-2} \mathrm{~h}^{-1}$

$\mathrm{L}_{\mathrm{t}} \quad$ Length of fiber in module ' $\mathrm{t}$ ', $\mathrm{m}$

$\mathrm{V}_{\mathrm{g}, \mathrm{t}} \quad$ Volume of stripping solution inside module ' $\mathrm{t}$ ', $\mathrm{m}^{3}$

$\Delta z \quad$ Infinitesimally small distance along the axial dimension of the module, $\mathrm{m}$

\section{Parameters}

K Scaling factor

$K_{\mathrm{eq}} \quad$ Equilibrium parameter of the extraction reaction, $\mathrm{mol}^{-2} \mathrm{~m}^{6}$

$\mathrm{K}_{\mathrm{L}} \quad$ Mass transfer coefficient for solute transfer through the aqueous phase stagnant layer, $\mathrm{m} \mathrm{h}^{-1}$

$\mathrm{K}_{\mathrm{LH}}$ Mass transfer coefficient for transport of hydrogen ions through the aqueous phase stagnant layer, $\mathrm{m} \mathrm{h}^{-1}$

$\mathrm{K}_{\mathrm{M}} \quad$ Membrane mass transport coefficient, $\mathrm{m} \mathrm{h}^{-1}$

$K_{O} \quad$ Solute mass transport coefficient in the organic phase stagnant layer, $\mathrm{m} \mathrm{h}^{-1}$

$\mathrm{N} \quad$ Number of divisions of the axial dimension of a membrane

$\beta_{\mathrm{a}} \quad$ Solute transfer coefficient for transfer of solute from the aqueous to the organic phase

$\beta_{g} \quad$ Solute transfer coefficient for the transfer of solute from the organic to the stripping phase

$\lambda \quad$ Lagrange multipliers 


\section{References}

(1) Alonso, A. I.; Lassahn, A.; Gruhn, G. Optimal design of non-dispersive solvent extraction processes. Comput. Chem. Eng. 2001, 25(2-3), 267.

(2) Ortiz, I.; Galán, B.; Irabien, A. Kinetic analysis of the simultaneous nondispersive extraction and backextraction of chromium (VI). Ind. Eng. Chem. Res. 1996, 35(4), 1369.

(3) Ortiz, I.; Galán, B.; Ibáñez, R. Método para la extracción y concentración simultáneas de compuestos de fases líquidas utilizando membranas microporosas. Spanish Patent, no. P9901559, 2005.

(4) Wiencek, J. M.; Hu, S. Emulsion liquid membrane extraction in a hollow fiber contactor. Chem. Eng. Technol. 2000, 23(6), 551.

(5) Ho, W. S.; Poddar, T. K. New membrane technology for removal and recovery of chromium from waste waters. Environ. Prog. 2001, 20(1), 44.

(6) Klaassen, R.; Jansen, A. E. The membrane contactor: environmental applications and possibilities. Environ. Prog. 2001, 20(1), 37.

(7) Urtiaga, A.; Abellán, M. J.; Irabien, J. A.; Ortiz, I. Membrane contactors for the recovery of metallic compounds. Modelling of copper recovery from WPO processes. J. Membrane. Sci. 2005, 257(1-2), 161.

(8) Bringas, E.; San Román, M. F.; Ortiz, I. Separation and recovery of anionic pollutants by the emulsion pertraction technology (EPT). Remediation of polluted groundwaters with $\mathrm{Cr}(\mathrm{VI})$. Ind. Eng. Chem. Res. 2006, 45, 4295.

(9) Corvalán, S. M.; Ortiz, I.; Eliceche, A. M. Optimal design of membrane processes for wastewater treatment and metal recovery. Comput. Chem. Eng. 2004, 28(1-2), 103.

(10)Eliceche, A.; Alonso, A.; Ortiz, I. Optimal operation of selective membrane separation processes for wastewater treatment. Comput. Chem. Eng. 2000, 24(9-10), 2115.

(11)Eliceche, A.; Corvalán, S. M.; Ortiz, I. Continuous operation of membrane processes for the treatment of industrial effluents. Comput. Chem. Eng. 2002, 4-5, 555.

(12) Ortiz, I.; San Román, M. F.; Corvalán, S. M.; Eliceche, A. M. Modeling and optimization of an emulsion pertraction process for removal and concentration of $\mathrm{Cr}(\mathrm{VI})$. Ind. Eng. Chem. Res. 2003, 42(3), 5891. 
(13)Eliceche, A. M.; Corvalán, S. M.; San Román, M. F.; Ortiz, I. Minimum membrane area of an emulsion pertraction process for $\mathrm{Cr}(\mathrm{VI})$ removal and recovery. Comput. Chem. Eng. 2005, 29(6), 1483.

(14) San Román, M. F.; Bringas, E.; Ortiz, I.; Grossmann, I. E. Optimal synthesis of an emulsion pertraction process for the removal of pollutant anions in industrial wastewater systems. Proceedings of the $15^{\text {th }}$ European Symposium on Computer Aided Process Engineering, Elsevier, Amsterdam, The Netherlands, 2005; p649.

(15) Wang, Y. P.; Smith, R. Design of distributed effluent treatment systems. Chem. Eng. Sci. 1994, 49(18), 3127.

(16) Galán, B.; Grossmann, I. E. Optimal design of distributed wastewater treatment networks. Ind. Eng. Chem. Res. 1998, 37, 4036.

(17) Lee, S.; Grossmann, I. E. A global optimization algorithm for nonconvex generalized disjunctive programming and applications to process systems. Comput. Chem. Eng. 2003, 27(11), 1557.

(18) Conn, A. R.; Gould, N. I. M.; Toint, Ph. L. Large-scale nonlinear constrained optimization. Proceedings of the Second International Conference on Industrial and Applied Mathematics, R. E. O’Malley, ed., Society for Industrial and Applied Mathematics, Philadelphia, PA, 1992;p51.

(19) Karuppiah, R.; Grossmann, I. E. Global optimization for the synthesis of integrated water systems in chemical processes. Comput. Chem. Eng. 2006, 30(4), 650.

(20) Guignard, M.; Kim, S. Lagrangean decomposition-A model yielding stronger lagrangean bounds. Math. Program. 1987, 39(2), 215.

(21) Gupta, A.; Maranas, C. D. A hierarchical Lagrangean relaxation procedure for solving midterm planning problems. Ind. Eng. Chem. Res. 1999, 38(5), 1937.

(22) Fisher, M. L. An applications oriented guide to Lagrangian -Relaxation. Interfaces, 1985, 15 (2), 10.

(23) Caroe, C. C.; Schultz, R. Dual decomposition in stochastic integer programming. Oper. Res. Lett. 1999, 24(1-2), 37 .

(24) Brooke, A.; Kendrick, D.; Meeraus, A.; Raman, R. GAMS: A user's guide, Release 2.50, GAMS Development Corporation, 1998. 
(25) Sahinidis, N. BARON: A general purpose global optimization software package. J. Global. Optim. 1996, 8(2), 201. 